\title{
The General Equilibrium Effects of Fiscal Policy: Estimates for the Euro Area
}

\author{
Lorenzo Forni Libero Monteforte Luca Sessa *
}

\begin{abstract}
This paper describes a dynamic stochastic general equilibrium model featuring a fraction of non-Ricardian agents in order to estimate the effects of fiscal policy in the Euro area. The model takes into account distortionary taxation on labor and capital income and on consumption, while expenditures are broken down into purchases of goods and services, compensation of public employees and transfers to households. A newly computed quarterly data set of fiscal variables is used. Our results point to the prevalence of mild Keynesian effects of public expenditures. In particular, although innovations in fiscal policy variables tend to be rather persistent, government purchases of goods and services and compensations for public employees have small and short-lived expansionary effects on private consumption, while innovations in transfers to households show a slightly more sizeable and lasting effect. The effects are more significant on the revenue side: decreases in labor income and consumption tax rates have sizeable effects on consumption and output, while a reduction in capital income tax favors investment and output in the medium run. Finally our estimates suggest that fiscal policy variables contribute little to the cyclical variability of the main macro variables. JEL: E32, E62. Keywords: fiscal policy, distortionary taxation, DSGE modeling, Bayesian estimation.
\end{abstract}

*lorenzo.forni@bancaditalia.it; libero.monteforte@bancaditalia.it; luca.sessa@bancaditalia.it. We benefited from comments by Alberto Alesina, Silvia Ardagna, Susanto Basu, Paul Cahu, Fabio Canova, Marco Del Negro, Rochelle Edge, Nicola Fuchs-Schündeln, Francesco Furlanetto, Jordi Galí, Teresa García-Milá, Peter Ireland, Paolo Manasse, Greg Mankiw, Domenico Marchetti, Roberto Perotti, Pedro Teles and seminar participants at Banca d'Italia, Bocconi, Bologna, Harvard and P. Fabra, and at CEF, Dynare, EEA, Moncasca and SED annual meetings, Macroeconomic Modeling Central Bank Workshop in Santiago de Chile, and Fiscal Stabilization Policies in a Monetary Union Conference at DG-Ecfin in Brussels. We would like to thank three anonymous referees for their advices, which have significantly improved the paper, and the members of the Banca d'Italia Research Dept. DSGE working group for their support, in particular Andrea Gerali, Claudia Miani, Stefano Neri and Massimiliano Pisani. The views expressed in this paper are those of the authors and do not involve the Bank of Italy. 


\section{Introduction}

This paper reconsiders the economic effects of fiscal policy using an estimated dynamic stochastic general equilibrium model for the Euro area. We try to better understand how these effects depend on the composition of expenditures and revenues, as well as on the interaction with monetary policy.

Recent years have witnessed significant changes in the fiscal position of both the United States and the Euro area. In many circumstances the main motivation behind these shifts has been related to cyclical considerations as policy makers have tried to support economic activity through fiscal stimulus. However, most of the discretionary measures undertaken, both on the spending and on the revenue side, were backed by little consensus among economists on their short to medium run effects. This lack of consensus stems from the difficulty economists have in building models able to replicate the main empirical regularities concerning fiscal variables.

Frictionless models with optimizing forward-looking agents, as RBC models, for example, seem to be ill-suited to study the effects of government spending. In this context, Baxter and King (1993) have shown that any increase in expenditures brings about - as the government intertemporal budget constraint has to be satisfied - an increase in the discounted value of future taxes. This amounts to a negative wealth effect on households that induces a decrease in their private consumption, a contemporaneous increase in labor supply and, therefore, a decrease in the marginal productivity of labor and in real wages; as in the model the steady state capital labor ratio does not change, investment will increase. These theoretical correlations do not square with the empirical evidence coming from applied research.

The debate on the empirical effects of fiscal policy shocks (in particular on the effects of government expenditure shocks on private consumption) is still unsettled. However, the disagreement mainly concerns the effects of increases in expenditures related to military buildups in the US - Perotti (2007) argues that the response of private consumption is positive, while Ramey (2008) that it is negative. For our purposes military buildups are somehow special events that do not really apply to the European case, as there is no relevant example of such events in European countries over our sample period (1980-2005). The literature on the effects of fiscal policy in "normal times" - that is abstracting from military buildups - mainly finds a moderately positive (or a non negative) response of private consumption to government expenditure shocks; ${ }^{1}$

\footnotetext{
${ }^{1}$ Among others, Perotti (2005) provides evidence of this kind for five OECD countries (USA, Germany, UK, Canada, Australia); Mountford and Uhlig (2005) have similar results for the US. Galí
} 
also employment and real wages tend to grow, while the response of private investment is generally negative. ${ }^{2}$

The new-Keynesian paradigm, which mainly adds real frictions and nominal rigidities to an RBC framework, displays the same wealth-effect mechanism that entails a reduction in private consumption and an expansion in labor supply following a government spending shock. ${ }^{3}$ In this context, however, real wages may increase as a result of an outward shift of the labor demand induced by the expanding demand in the presence of sticky prices (with a reduction in price markups).

In order to fill the gap with the evidence, the literature has recently moved away from the representative infinitely-lived rational agent. In particular Mankiw (2000) has argued that a model where Ricardian and non-Ricardian agents (that cannot save or borrow and therefore consume their income period by period) coexist is better suited for fiscal policy analysis with respect to both neoclassical and overlapping generations models. ${ }^{4}$ Building on this framework, Galí, López-Salído and Vallés (2007, henceforth GLSV) add rule-of-thumb agents to a standard new-Keynesian model. They show that both price stickiness and the presence of rule-of-thumb consumers are necessary elements in order to have a positive response of private consumption for reasonable calibrations of the parameters. "Rule-of-thumb consumers partly insulate aggregate demand from the negative wealth effects generated by the higher levels of (current and future) taxes needed to finance the fiscal expansion, while making it more sensitive to current disposable income. Sticky prices make it possible for real wages to increase (or, at least, to decline by a smaller amount) even in the face of a drop in the marginal product of labor, as the price markup may adjust sufficiently downward to absorb the resulting gap. The combined effect of a higher real wage and higher employment raises current labor income and hence stimulates the consumption of rule-of-thumb

et al. (2007) provide an extensive review of literature on the topic.

${ }^{2}$ On the response of employment and real wages, see Pappa (2005) for an analysis on US data. On the response of investment, Alesina et al. (2002) have shown, on a large sample of OECD countries over the period 1960-2002, the negative effect on investment of a variety of government spending shocks (in particular related to transfers to households and to the public wage bill). Also Perotti (2005) shows that the response of investment is negative in the US and, after 1980, in Germany.

${ }^{3}$ On this see Goodfriend and King (1997) and Linnemann and Schabert (2003).

${ }^{4}$ As Mankiw (2000), pg. 124, puts it "A better model would acknowledge the great heterogeneity in consumer behavior that is apparent in the data. Some people have long time horizons, as evident by the great concentration of wealth and the importance of bequests in aggregate capital accumulation. Other people have short time horizon, as evidenced by the failure of consumption-smoothing and the prevalence of households with near zero net worth." 
households". 5,6

In this paper we contribute to the debate on the macroeconomic effects of fiscal policy by estimating on Euro area data a DSGE model which puts the idea of GLSV into the framework of Christiano, Eichenbaum and Evans (2005). The latter includes a number of frictions proved to be useful for estimation purposes, as shown in particular on Euro area data by Smets and Wouters (2003, henceforth SW).$^{7}$

We extend this framework with a relatively rich description of the fiscal policy side. In particular, for government revenues we consider and estimate fiscal policy rules defined on distortionary tax rates, while previous literature (GLSV, and Coenen and Straub, 2005, henceforth CS) had essentially focused on lump-sum taxes. In order to do so, we compute quarterly average effective tax rates on labor income, capital income and consumption for the Euro area following the methodology of Mendoza, Razin and Tesar (1994). ${ }^{8}$

On the expenditure side, we take into consideration the fact that the variable generally used in the literature as a proxy for government purchases of goods and services, that is government consumption from National Accounts data, includes both purchases of goods and services and compensations for government employees, as recognized earlier by Rotemberg and Woodford (1992) and later by Finn (1998). In fact, in the case of the Euro area over the last twenty five years (the sample period we consider), the

\footnotetext{
${ }^{5}$ GLSV pg. 260.

${ }^{6}$ As another alternative to a model with a representative infinitely-lived rational agent, Romanov (2003), Sala (2004) and Cavallo (2007), among others, consider agents with a finite horizon by introducing a constant probability of dying à la la Blanchard (1985). The idea is that, although higher government expenditures will increase the level of expected future taxes, agents - while fully benefiting from the expansion in expenditures - will not likely live long enough to pay their entire share of the financing. However, since the Keynesian effects of expenditures shocks depend essentially on the probability of (or share of the population) dying before paying taxes and this probability is reasonably small over the short to medium term, these models cannot replicate the positive response of private consumption to a government spending shock.

${ }^{7}$ Differently from GLSV and due to the fact that we are interested in estimating the model, we assume sticky wages. Sticky wages might be thought to work against the positive response of private consumption after a government expenditure shock, as real wages would increase less after the shock or even decrease. Our estimates confirm a more muted response of real wages, but still positive. This goes along with a lower increase in marginal costs and inflation, triggering a smaller increase in the real interest rate and a reduced impact decrease in Ricardians' consumption. Therefore, as Furlanetto (2006) shows in the GLSV model, sticky wages are not bound to induce a negative effect of government expenditure innovations on total private consumption.

${ }^{8}$ Appendix B provides a detailed description of the data used, including the methodology we have employed to obtain quarterly series, and some comparison between our data and alternative sources.
} 
employee's compensations share of government expenditures averaged $60 \%$ approximately. While government purchases of goods and services is a direct component of aggregate demand, compensations of government employees affect the economy mainly through their effects on employment and wages. We therefore define government consumption excluding compensations for public employees (an aggregate that we will label government purchases) and model public employment separately.

The model is estimated using Bayesian inference methods on the Euro area data from 1980 to 2005. Bayesian technique - as forcefully claimed by Fernandez-Villaverde and Rubio-Ramirez (2006) - is now the standard tool for the estimation of DSGE models. Fernandez-Villaverde and Rubio-Ramirez (2004) show how, in practical applications, the Bayesian approach delivers very strong performance, especially on small samples.

Our paper tries to assess the response of the main macro variables to a wide range of fiscal shocks, including revenue ones. We are not concerned only with the effects of government spending shocks on private consumption, although the issue has recently attracted considerable attention. In relation to this latter issue, we would like to stress that our estimation strategy allows also for a negative response, as we discuss in some detail in section 5.4 below.

Although fiscal policy is run at national level, the focus of this paper is on the Euro area. As cross country spillover effects from fiscal policy shocks tend to be limited, ${ }^{9}$ shocks in one single country mainly affect that country's variables, so that the effect on Euro area variables mainly depends on the weight of the country within the Euro area. Our estimated effects should therefore be interpreted as the (weighted) average effects of fiscal shocks across Euro area countries. On the other hand, focusing on the Euro area as a whole has advantages: first, we can easily take into account the role of the common monetary policy; second, we can keep the model relatively simple and disregard all the theoretical and empirical issues related to the analysis of a single country in a monetary union; third, we can build on a model specification, the one proposed by SW, proven to match the Euro area data quite well; last, there is not an obvious candidate country for our study, as there are no official quarterly data available for any of the Euro area countries previous to 1999.

To our knowledge, this is the first paper that estimates a medium scale DSGE model with a detailed role for fiscal policy (featuring both distortionary taxes and detailing expenditures in its main components) on Euro area data. We use both state of the art

\footnotetext{
${ }^{9}$ Evidence in this regard can be found in Marcellino (2006) and De Bandt and Mongelli (2002). For an analysis of fiscal policy in a two-region currency union model using a framework similar to the one of this paper, see Forni, Gerali and Pisani (2008).
} 
econometric techniques for the estimation and a newly computed quarterly data set for fiscal policy variables (as government sector data in the Euro area are mainly available on an annual basis). We believe that the use of a rich set of data (especially for the government sector that is the focus of our paper) is necessary for a proper identification of parameters and shocks. In particular, having data on distortionary taxes can potentially improve the estimates of certain shocks: for example, it might help disentangling the effects of a shock affecting the consumption-leisure intratemporal trade-off from those of a change in the labor income tax rate, or the effects of an investment shock from those of a capital income tax rate shock. Our approach, therefore, overcomes some of the weaknesses related to the interpretation of shocks pointed out by Chari, Kehoe and McGrattan (2008).

Our results point to a significant share of non-Ricardian agents (between 30 and 40\%) and to the prevalence of mild Keynesian effects of public expenditures. In particular, although innovations in fiscal policy variables tend to be rather persistent, government purchases of goods and services and compensations for public employees have small and short lived expansionary effects on private consumption, while innovations in transfers to households show a slightly more sizeable and lasting effect. The effects are more significant on the revenue side: decreases in labor income and consumption tax rates have sizeable effects on consumption and output, while a reduction in the capital income tax favors investment and output in the medium run. Finally our estimates suggest that fiscal policy variables contribute little to the cyclical variability of the main macro variables.

The paper is organized as follows. Section 2 describes in detail the model and our assumptions regarding policies. Section 3 sketches the techniques we use to solve and estimate the model, and describes the data and the assumptions regarding prior distributions. Section 4 presents our estimated parameter distributions, that are then used in section 5 to discuss the effects of fiscal policy innovations. In section 6 we summarize our results.

\section{The setup}

\subsection{Production and technology}

In the private sector there is a continuum of firms $j$ each producing one differentiated final good with the following Cobb-Douglas technology defined in terms of homogeneous labor input $L_{t}^{p}$ (where the superscript $p$ refers to the employment level in the private 
sector) and rented capital services $K_{t}$ :

$$
Y_{t}(j)=A_{t} K_{t}(j)^{\alpha}\left(Z_{t} L_{t}^{p}(j)\right)^{1-\alpha}
$$

where $A_{t}$ is a stationary technology shock and $Z_{t}$ a labor-augmenting permanent one. For the processes describing technology we follow, among others, Adolfson et al. (2007) and assume:

$$
\begin{gathered}
\log \left(A_{t}\right)=\rho^{A} \log \left(A_{t-1}\right)+\varepsilon_{t}^{A} \\
\log \left(\nu_{t}\right)=\left(1-\rho^{\nu}\right) \log (\nu)+\rho^{\nu} \log \left(\nu_{t-1}\right)+\varepsilon_{t}^{\nu}
\end{gathered}
$$

where $\nu_{t}=Z_{t} / Z_{t-1}$ and $\nu$ is the steady state growth rate of $Z_{t}$. In the following we will present the model expressed in terms of detrended (lowercase) variables, so that for a generic variable $X_{t}$ we will define:

$$
x_{t} \equiv \frac{X_{t}}{Z_{t}}
$$

From the solution of firm $j$ 's static cost minimization problem, we have input demands

$$
\begin{gathered}
k_{t}(j)=\frac{y_{t}(j)}{A_{t}}\left(\frac{W_{t}}{R_{t}^{k}} \frac{\alpha}{1-\alpha}\right)^{1-\alpha} \nu_{t} \\
L_{t}^{p}(j)=\frac{y_{t}(j)}{A_{t}}\left(\frac{W_{t}}{R_{t}^{k}} \frac{\alpha}{1-\alpha}\right)^{-\alpha}
\end{gathered}
$$

and, defining $\zeta=(1-\alpha)^{\alpha-1} \alpha^{-\alpha}$, an expression for the nominal marginal cost (here equal to the average one and hence common to all firms)

$$
M C_{t}=\frac{\zeta W_{t}^{1-\alpha} R_{t}^{k^{\alpha}}}{A_{t}}
$$

Each firm chooses its own net (of consumption taxes) price $\widetilde{P}_{t}(j)$ to maximize intertemporal profits defined as the difference between total revenues and total costs (inclusive of a price adjustment cost, scaled in terms of wholesale total output)

$$
\max _{\left\{\widetilde{P}_{t}(j)\right\}} E_{0} \sum_{t=0}^{\infty} Q_{0, t} Z_{t}\left[\widetilde{P}_{t}(j) y_{t}(j)-M C_{t} y_{t}(j)-\frac{\kappa}{2}\left(\frac{\widetilde{P}_{t}(j)}{\widetilde{P}_{t-1}(j)}-\pi\right)^{2} \widetilde{P}_{t} y_{t}\right]
$$

subject to demand-determined output. $Q_{0, t}$ is the stochastic discount factor for Ricardian households (the only share-owners) and $y_{t}(j)$ is the (detrended) demand faced by firm $j$. 


\subsection{Consumers Problem}

The economy is populated by a measure one of households. A fraction $\gamma$ of them are non-Ricardians: they do not have access to financial or capital markets. Asset markets (not modelled) are assumed to be complete. Ricardian households are the only owners of assets, including capital, which is rented to firms.

All consumers have a preference for variety: for each household $i$, the consumption index is

$$
c_{t}(i)=\left[\int_{0}^{1} c_{t}(i, j)^{\frac{\theta_{c}-1}{\theta_{c}}} d j\right]^{\frac{\theta_{c}}{\theta_{c}-1}}
$$

where $c_{t}(i, j)$ is $i$ 's consumption of the good produced by firm $j$. The maximization of $c_{t}(i)$ w.r.t. $c_{t}(i, j)$ for a given total expenditure leads to a set of demand functions of the type

$$
c_{t}(i, j)=\left(\frac{P_{t}(j)}{P_{t}}\right)^{-\theta_{c}} c_{t}(i)
$$

where $P_{t}(j)$ is the price of the good produced by firm $j$ gross of consumption taxes. An aggregator identical to (6) is also assumed for both real government purchases $c_{t}^{g}$ and investment $i_{t}$, and for each of them isoelastic demand functions of the form of (7) obtain. From aggregation over agents, aggregate demand for each component still has the form of (7) and total demand for a good produced by firm $j$ can be expressed as $y_{t}(j)=c_{t}(j)+c_{t}^{g}(j)+i_{t}(j)$. Therefore each firm will face an isoelastic demand function with price elasticity $\theta_{c}$ for its total demanded output.

Conditional on optimal behavior, it will be true that $\int_{0}^{1} P_{t}(j) c_{t}(i, j) d j=P_{t} c_{t}(i)$, and similarly for public consumption and investment, although for the latter it is assumed that no indirect tax is levied, so that the relevant price index is $\widetilde{P}_{t}=P_{t} /\left(1+\tau_{t}^{c}\right)$.

\subsubsection{Ricardian households}

Lifetime utility of the $i$-th Ricardian household $(R)$ is a separable function of its consumption $c_{t}^{R}(i)$ and labor $L_{t}^{R}(i)$ given by:

$$
E_{0} \sum_{t=0}^{\infty} \beta^{t} \varepsilon_{t}^{b}\left[\log \left(c_{t}^{R}(i)-h \frac{c_{t-1}^{R}}{\nu_{t}}\right)-\varepsilon_{t}^{L} \frac{1}{1+\sigma_{L}} L_{t}^{R}(i)^{1+\sigma_{L}}\right]
$$

Ricardian households have external habits in consumption with parameter $h \in[0,1)$ : $c_{t-1}^{R}$ is lagged aggregate per capita (and detrended) consumption. Two demand shifters are assumed: $\varepsilon_{t}^{b}$ affects the overall level of utility in period $t$ while $\varepsilon_{t}^{L}$ affects the consumption-leisure intratemporal trade-off. The nominal flow budget constraint for 
Ricardian agent $i$ is given by

$$
\begin{aligned}
& \left(1-\tau_{t}^{w}\right) w_{t}(i) L_{t}^{R}(i)+\left(1-\tau_{t}^{k}\right)\left[R_{t}^{k} \frac{\bar{k}_{t}^{R}(i)}{\nu_{t}} u_{t}(i)+d_{t}^{R}(i)\right]+\frac{b_{t}^{R}(i)}{\nu_{t}}+t r_{t}^{R}(i)+\frac{\tau_{t}^{c}}{1+\tau_{t}^{c}} P_{t} i_{t}^{R}(i)= \\
& =P_{t} c_{t}^{R}(i)+P_{t} i_{t}^{R}(i)+\frac{b_{t+1}^{R}(i)}{R_{t}}+P_{t} \psi\left(u_{t}(i)\right) \frac{\bar{k}_{t}^{R}(i)}{\nu_{t}}+\frac{\phi}{2}\left(\frac{w_{t}(i)}{w_{t-1}(i)} \nu_{t}-\pi\right)^{2} w_{t}
\end{aligned}
$$

where $\left(1-\tau_{t}^{w}\right) w_{t} L_{t}^{R}$ is net labor income, $\left(1-\tau_{t}^{k}\right) R_{t}^{k} \bar{k}_{t}^{R} u_{t} / \nu_{t}$ is net nominal income from renting capital services $k_{t}^{R}=\bar{k}_{t}^{R} u_{t}$ (where the bar indicates physical units of capital, while $u_{t}$ is utilization intensity) to firms at the rate $R_{t}^{k}, d_{t}^{R}$ are dividends distributed by firms to Ricardians (by assumption, the only firms' owners). The fiscal authority makes net lump-sum transfers $t r_{t}$ and finances its expenditures by issuing one period maturity discount nominal bonds $b_{t}$ and by levying taxes on labor income $\left(\tau_{t}^{w}\right)$, capital income $\left(\tau_{t}^{k}\right)$ and consumption $\left(\tau_{t}^{c}\right)$. Consumption tax introduces a wedge between the producer price index $\widetilde{P}_{t}$ and the consumers one $P_{t}=\left(1+\tau_{t}^{c}\right) \widetilde{P}_{t}$. We assume that no indirect taxes are paid on purchases of investment goods, so that the price index of investment goods is the wholesale price $\widetilde{P}_{t}$. Instead of having two price levels in the consumers' problem, we include among the uses (r.h.s. of the budget constraint) the investment expenditure expressed in terms of prices gross of taxes $P_{t} i_{t}^{R}$ and compensate it with a rebate equal to $\frac{\tau_{t}^{c}}{1+\tau_{t}^{c}} P_{t} i_{t}^{R}$, so that the difference between the two is equal to the actual expenditure on investment goods $\widetilde{P}_{t} i_{t}^{R}$. Uses also feature the amount of government bonds that Ricardian households carry over to the following period, discounted by the nominal gross interest rate $R_{t}$. Finally, adjustment costs are introduced on the household choices of the nominal wage $w_{t}$ and of capacity utilization $u_{t}$. The first is incurred if the nominal wage deviates from the steady state path (along which gross wage inflation $\pi^{w}$ is assumed equal to gross price inflation $\pi$ ) and is expressed in terms of the equilibrium wage rate $w_{t}$ (see Kim, 2000). The second is incurred if the level of capital utilization is different from its steady state value of 1 ; this cost is described by an increasing convex function $\psi\left(u_{t}\right)$, with $\psi(1)=0$.

The physical capital accumulation law is

$$
\bar{k}_{t+1}^{R}(i)=(1-\delta) \frac{\bar{k}_{t}^{R}(i)}{\nu_{t}}+\left[1-s\left(\frac{\varepsilon_{t}^{i} i_{t}^{R}(i)}{i_{t-1}^{R}(i)} \nu_{t}\right)\right] i_{t}^{R}(i)
$$

where not all new investment gets transformed into capital and the term $s\left(\frac{\varepsilon_{t}^{i} i_{t}^{R}}{i_{t-1}^{R}} \nu_{t}\right) i_{t}^{R}$ describes (in terms of capital loss) the cost of adjustment for varying the investment level with respect to the previous period, a cost which is subject to a specific efficiency shock $\varepsilon_{t}^{i} \cdot 10$

\footnotetext{
${ }^{10}$ As in Christiano et al. (2005), s(.) has the general properties $s(1)=s^{\prime}(1)=0$ and $s^{\prime \prime}(1)>0$.
} 


\subsubsection{Non-Ricardian households}

Non-Ricardian households have been modeled in various ways in the literature, leading to different responses of their consumption to changes in their current disposable income. Some authors have assumed that non-Ricardian households cannot participate in capital markets, but they can still smooth consumption by adjusting their holding of money (consumption smoothing will be less than complete as the return from money holding has a negative real return). In this latter case, as for example Coenen, McAdam and Straub (2008) show, it is very difficult to get a non negative response of private consumption to a government expenditure shock as the response of non-Ricardian consumers is very similar to that of Ricardians.

Other authors have shown that assumptions implying stronger responses of nonRicardian agent's consumption to variations in disposable income are necessary in order to allow for the possibility of obtaining a positive response of private consumption to government expenditure shocks. In particular, following Campbell and Mankiw (1989), GLSV assume that in each period non-Ricardian agents consume their current income; in their work, the strong response of non-Ricardian consumption to disposable income variations is a necessary condition (but not sufficient) to obtain a positive response of total consumption to government spending shocks. In this paper we follow this latter approach and assume that non-Ricardian households $(N R)$ simply consume their aftertax disposable income, as originally proposed by Campbell-Mankiw (1989). That is, their budget constraint is simply:

$$
P_{t} C_{t}^{N R}(i)=\left(1-\tau_{t}^{w}\right) w_{t}(i) L_{t}^{N R}(i)+t r_{t}^{N R}(i)
$$

We would like to stress that this modeling of non-Ricardians does not impose a positive response of total private consumption to government expenditure shocks. The response will depend, among other things, on the value of the share of non-Ricardians, $\gamma$, that we estimate. As we will show, for low values of $\gamma$ the response of consumption is in fact negative.

\subsection{The labor market}

The labor market is monopolistically competitive, and equilibrium employment is demand-determined. For each type of differentiated labor service, supply comes from both Ricardian and non-Ricardian households and demand gets uniformly allocated among them. Labor is an input for both the public and the private sector. Public sector labor demand is modeled as an autoregressive exogenous shock in logs with i.i.d. 
error term, of the form

$$
\log L_{t}^{g}=\rho_{L g} \log L_{t-1}^{g}+\left(1-\rho_{L g}\right) \log L^{g}+\varepsilon_{t}^{L g}
$$

and one has $L_{t}^{g}=\int_{0}^{1} L_{t}^{g}(i) d i$. We assume that the wage rate in the public sector is equal to the one prevailing in the private sector. ${ }^{11}$ Hours can be moved costlessly across the two sectors and $L_{t}^{g}$ and $L_{t}^{p}$ are perfect substitutes in the utility function, that is $L_{t}=L_{t}^{g}+L_{t}^{p}$. This setup is very similar to the one considered by Cavallo (2007), although in a different context.

In the private sector labor market, a perfectly competitive firm buys the differentiated individual labor services supplied by households and transforms them into an homogeneous composite labor input that, in turn, is sold to good-producing firms. This 'labor packer' is a CES aggregator of differentiated labor services which solves:

$$
\begin{gathered}
\max _{L_{t}^{p}(i)} L_{t}^{p}=\left[\int_{0}^{1} L_{t}^{p}(i)^{\frac{\theta_{L}-1}{\theta_{L}}} d i\right]^{\frac{\theta_{L}}{\theta_{L}-1}} \\
\text { s.t. } \quad \int_{0}^{1} w_{t}(i) L_{t}^{p}(i) d i=\bar{E}_{t}
\end{gathered}
$$

for a given level of the wage bill $\bar{E}_{t}$. The solution gives the demands for each kind of differentiated labor service in the private sector $L_{t}^{p}(i)$ :

$$
L_{t}^{p}(i)=\left(\frac{w_{t}(i)}{w_{t}}\right)^{-\theta_{L}} L_{t}^{p}
$$

where $L_{t}^{p}$ is total private sector labor.

The representative Ricardian household solves the intertemporal problem of setting optimally a wage for its type $i$ labor, having regard to the labor demand constraint (14) and of the current and future costs of misalignments of wage growth from steady state inflation. Given that, by assumption, non-Ricardians do not have an intertemporal optimizing behavior, following Erceg et al. (2005) our baseline model assumes that the non-Ricardian wage rate simply equals the average of the Ricardians. This way, since all households face the same labor demand in the private sector where wages are set, both the wage rate and hours worked will be equal for every agent in the economy. Although simplifying, this assumption imposes that the hours worked by non-Ricardians respond to shocks in the same way as those worked by Ricardians. In particular, Ricardian labor effort will respond to a public expenditure shock in

\footnotetext{
${ }^{11}$ This assumption is not far from reality. In fact, hourly wages in the public sector tend to track private sector ones, at least over medium terms horizons.
} 
the standard way: a, say, positive public expenditure shock will induce a standard negative wealth effect that will lead to an increase in labor supply. By assumption, the response will be the same for non-Ricardians, sustaining their labor income and therefore amplifying any Keynesian effect following the shock.

Hence, we consider as a robustness check a more general version of the labor market, able to recognize a role for non-Ricardian preferences in labor choice even if they cannot optimize intertemporally, and in which non-Ricardians do not fully inherit the labor supply consequences from the wealth effect of Ricardians. In particular, we follow the approach proposed by GLSV, according to which a union representing the preferences of both Ricardian and non-Ricardian agents sets wages in a monopolistically competitive labor market. Union bargaining is consistent with the characteristic of the European labor market and moreover will deliver a single wage and employment level (which is desirable for estimation purposes). Details and results of this alternative model are reported in Appendix A. As the results are not substantially different, we have stuck to the simple formulation as our baseline model.

\subsection{Fiscal policy}

Estimates concerning the effects of fiscal policy for the Euro area are usually constrained by the lack of quarterly data on government accounts. Eurostat has recently started to release quarterly data on general government accounts, but only starting from 1999, i.e. a period too short to be used for our purposes. The only quarterly data series easily available are government consumption $(G)$ and public employment. As we have computed quarterly data for government purchases of goods and services, transfers to families, total revenues and average effective tax rates, we can model the fiscal policy block with more detail than previous work. First, we can distinguish within expenditures and revenues. Moreover, estimating average effective tax rates allows us to use proportional distortionary taxation, a feature that is more realistic, and more appropriate for estimation purposes than assuming lump-sum taxes. ${ }^{12}$

\footnotetext{
${ }^{12}$ As we use average effective tax rates, instead of marginal tax rates, we might have a potential misspecification problem for labor income taxes, as these are generally progressive (capital income and consumption taxes, instead, tend to be proportional). However, estimated elasticities of the labor income tax revenues are not very far from 1 in the Euro area (1.3 for Germany, 0.6 for France, 0.8 for Italy and 1.1 for Spain, which on a weighted average basis is close to 1; see for these numbers van den Noord, P., 2000). This implies that average effective and average marginal tax rate tend to comove and that the mild pro-cyclicality in tax rates that we find (see section 2.4.1) is not due to the way we estimate average tax rates. Also results in Mendoza, Razin and Tesar (1994) support the view that the dynamics of average and marginal tax rates are not very different. As we demean the variables,
} 
We consider the following budget constraint (in detrended form):

$$
\left[\frac{b_{t+1}}{R_{t}}-\frac{b_{t}}{\nu_{t}}\right]=c_{t}^{g}+w_{t} L_{t}^{g}+t r_{t}-t_{t}
$$

where $c_{t}^{g}$ is government purchases of goods and services (assumed to be pure waste), $w_{t} L_{t}^{g}$ is compensation for public employees and $t r_{t}$ are transfers to households. Total government revenues $t_{t}$ are given by the following identity:

$$
t_{t}=\tau_{t}^{w} w_{t} L_{t}+\frac{\tau_{t}^{c}}{1+\tau_{t}^{c}}\left[P_{t} c_{t}+c_{t}^{g}\right]+\tau_{t}^{k}\left[R_{t}^{k} \frac{k_{t}}{\nu_{t}}+d_{t}\right]
$$

where tax rates on labor income, capital income and consumption are assumed to be determined according to the following rules:

$$
\begin{aligned}
\log \tau_{t}^{w} & =\rho_{\tau^{w}} \log \left(\tau_{t-1}^{w}\right)+\left(1-\rho_{\tau^{w}}\right) \eta_{\tau^{w}} \log \left(\tilde{B}_{t}\right)+\varepsilon_{t}^{\tau^{w}} \\
\log \tau_{t}^{c} & =\rho_{\tau^{c}} \log \left(\tau_{t-1}^{c}\right)+\left(1-\rho_{\tau^{c}}\right) \eta_{\tau^{c}} \log \left(\tilde{B}_{t}\right)+\varepsilon_{t}^{\tau^{c}} \\
\log \tau_{t}^{k} & =\rho_{\tau^{k}} \log \left(\tau_{t-1}^{k}\right)+\left(1-\rho_{\tau^{k}}\right) \eta_{\tau^{k}} \log \left(\tilde{B}_{t}\right)+\varepsilon_{t}^{\tau^{k}}
\end{aligned}
$$

where $\tilde{B}_{t}=B_{t} / P_{t} Y_{t}$ and each $\varepsilon_{t}^{\tau}$ is an i.i.d. innovation. Detrended expenditure items, $c_{t}^{g}$ and $t r_{t}$, are assumed to follow exogenous log linear AR(1) processes in real terms as for $L_{t}^{g}$, with i.i.d. innovations $\varepsilon_{t}^{c g}$ and $\varepsilon_{t}^{t r}$.

As for steady state values, based on sample averages we set purchases of goods and services at $10 \%$ of output, debt at $60 \%$ (on a yearly basis) and $L^{g}$ equal to $20 \%$ of total employment. Steady state values for tax rates are assumed to be simply the averages over the sample period of our estimates of average effective tax rates (approximately equal to $16 \%$ for consumption taxes, $19 \%$ for capital income taxes, $45 \%$ for labor income taxes). Given these figures, the steady state value for transfers is set residually so as to satisfy the government budget constraint (it turns out to be equal to $16.5 \%$ of output).

\subsubsection{Some remarks on the fiscal policy rules}

In our benchmark specification we assume that taxes are set in order to keep real debt dynamics (as a share of GDP) under control. This is consistent with the idea that debt stabilization is an important motive in the conduct of fiscal policy. Moreover, as Schmitt-Grohé and Uribe (2006) show in a model very similar to ours, such linear tax rules, where tax rates depend on the debt to GDP ratio and output gap, can in fact approximate optimal rules.

we are mainly concerned with the dynamics. 
To explore the issue of the cyclical stabilization role of tax rates, we added to our policy rules the growth rate of detrended output (i.e., the gap between GDP growth and trend growth). The estimates show that the coefficients relating tax rates to this measure of gap are in general positive (suggesting pro-cyclical changes in tax rates) but too small to significantly affect the results. ${ }^{13}$ We have also experimented adding measures of expenditures (transfers, government purchases of good and services, government wage bill) in the tax rules and found that the corresponding coefficients are not well-identified and in general not sizeable.

As for expenditures, we are assuming they are all exogenous $\mathrm{AR}(1)$ processes. The inclusion of measures of economic activity in the process describing expenditures is potentially important, as an expansionary fiscal shock could bring about an increase in activity and employment and therefore a reduction in automatic stabilizers (as unemployment expenditures, which are included in transfers to households). The latter could in turn offset the increase in disposable income of non-Ricardian households coming from the increase in labor income.

We have therefore experimented with introducing fiscal rules on expenditures while at the same time assuming exogenous processes for the tax rates. In general, the parameters relating expenditure items with the debt ratio and the output growth are estimated to be negative and very small (and, with the exception of the response of transfers to debt, also not very well-identified). We have used these estimated rules on expenditure items to assess the responses to tax rates and expenditure shocks and found results that are not qualitatively different from the ones obtained under our baseline specification (where we define fiscal rules on tax rates). In particular, the estimated response of transfers to output growth is relatively mild and not able to change in any significant way our estimated response of private consumption to government expenditure shocks.

Finally, another relevant issue is whether we are able to properly identify fiscal policy innovations, in particular tax rates innovations. In this respect, we follow the approach that is standard in the literature on monetary policy, that is to augment the tax rules with an i.i.d. error term and to assume that this error represents an unexpected change in policy. However, it might be argued that fiscal policy is different, as it suffers more than monetary policy from announcement effects and implementation lags. Although

\footnotetext{
${ }^{13}$ There is some evidence on the response of the overall budget deficit to the cycle (as measured for example by the output gap) on a yearly basis, although Galí and Perotti (2003) document that the response is at best weak. The evidence is more supportive of the stabilization role of fiscal policy when estimates are conducted using real time data; see on this Forni and Momigliano (2004).
} 
this criticism cannot be entirely disregarded, it is difficult to believe that changes in effective tax rates on a quarterly basis could be fully anticipated. Moreover, we assume that a share of agents consume their current disposable income. For these agents, even changes that are announced in advance will not have any effect prior to their realization.

\subsection{Monetary policy}

The monetary policy specification is in line with SW and assumes that the central bank follows an augmented Taylor interest rate feedback rule characterized by a response of the nominal rate $R_{t}$ to its lagged value, to the gap between lagged inflation $\pi_{t-1}$ and steady state inflation $\pi$, to the gap between contemporaneous (detrended) output $y_{t}$ and its steady state value, to changes in inflation $\Delta \pi_{t}=\pi_{t}-\pi_{t-1}$ and to output growth $\Delta y_{t}=y_{t}-y_{t-1} \cdot{ }^{14}$ In log-linearized form we have:

$$
\widehat{R}_{t}=\rho_{R} \widehat{R}_{t-1}+\left(1-\rho_{R}\right)\left(\rho_{\pi} \widehat{\pi}_{t-1}+\rho_{y} \widehat{y}_{t}\right)+\rho_{\Delta \pi} \widehat{\Delta \pi}_{t}+\rho_{\Delta y} \widehat{\Delta y_{t}}+\widehat{\varepsilon}_{t}^{m}
$$

The monetary policy shock $\varepsilon_{t}^{m}$ is assumed to be i.i.d. ${ }^{15,16}$

\footnotetext{
${ }^{14} \mathrm{We}$ follow SW and others and assume that the Taylor rule is a good description of the conduct of monetary policy also before the Euro, during the period characterized by the European Monetary System (that provided, anyway, some coordination in monetary policy across European countries). Also, as discussed in section 3.1, we de-trended the inflation rate data with a linear spline. This is equivalent to assuming a varying target inflation rate for the monetary authority, and should take care of the transition period from the EMS to the single monetary policy.

${ }^{15}$ In new-Keynesian models with non-Ricardian agents the Taylor principle (that states $\rho_{\pi}>1$ as a sufficient condition for local determinacy) might not hold. For example, Bilbiie (2006) argues, in a model without capital, that determinacy requires a muted (less than one for one) response of nominal rate to inflation (the so called inverted Taylor principle). On the other hand, Galí et al. $(2004,2007)$ show that, when both price stickiness and the share of non-Ricardians are high, the Taylor principle should be reinforced (reinforced Taylor principle), that is determinacy requires a response of nominal rate to inflation much greater than one. In our model, however, the Taylor principle holds. The reason is that both Bilbiie (2006) and Galí et al. (2004, 2007) assume flexible wages, while we assume sticky wages. As Colciago (2006) has shown, with (reasonable amounts of) wage stickiness the Taylor principle is restored.

${ }^{16}$ We have experimented with different specifications of the Taylor rule and different priors on its coefficients (for details refer to the working paper version, Forni et al. 2007) and found that the estimated effects of fiscal shocks are not substantially affected. This suggests that controlling for monetary policy is not crucial when estimating the effects of fiscal policy shocks, a result in line with Perotti (2005).
} 


\subsection{Aggregations and market clearing}

The aggregate per-capita level of any household quantity variable $x_{t}(i)$ is given by

$$
x_{t}=\int_{0}^{1} x_{t}(i) d i=(1-\gamma) x_{t}^{R}+\gamma x_{t}^{N R}
$$

as households within each of the two groups are identical. Therefore, as an example, aggregate consumption is given by $c_{t}=(1-\gamma) c_{t}^{R}+\gamma c_{t}^{N R}$, while aggregate capital, as any variable which relates only to Ricardians, by $\bar{k}_{t}=(1-\gamma) \bar{k}_{t}^{R}$. Equilibrium in the goods market requires:

$$
y_{t}=A_{t}\left(\frac{k_{t}}{\nu_{t}}\right)^{\alpha}\left(L_{t}^{p}\right)^{1-\alpha}=c_{t}+i_{t}+c_{t}^{g}+a d j_{t}
$$

where $a d j_{t}$ stands for (detrended) adjustment costs in real terms,

$$
a d j_{t}=\frac{\phi}{2}\left(\pi_{t}^{w} \nu_{t}-\pi\right)^{2} \frac{w_{t}}{P_{t}}+\psi\left(u_{t}\right) \frac{\bar{k}_{t}}{\nu_{t}}+\frac{\kappa}{2}\left(\tilde{\pi}_{t}-\pi\right)^{2} \frac{y_{t}}{1+\tau_{t}^{c}}
$$

with $\pi_{t}^{w} \equiv w_{t} / w_{t-1}$ and $\widetilde{\pi}_{t} \equiv \widetilde{P}_{t} / \widetilde{P}_{t-1}$. Market clearing conditions in capital and private labor markets are obtained by setting firms' demands (2) and (3) equal to households' supplies.

\section{Solution and estimation}

Ricardian households maximize (8) subject to (9) and (10) with respect to $c_{t}^{R}, b_{t+1}^{R}$, $w_{t}, i_{t}^{R}, \bar{k}_{t+1}^{R}, u_{t}$, and the two Lagrangian multipliers, $\lambda_{t}$ and $\mu_{t}$ respectively. In the symmetric equilibrium, the corresponding first order conditions are

$$
\begin{gathered}
\frac{\varepsilon_{t}^{b}}{\left(c_{t}^{R}-h c_{t-1}^{R} / \nu_{t}\right)}=\lambda_{t} P_{t} \\
\lambda_{t}=\beta R_{t} E_{t}\left[\frac{\lambda_{t+1}}{\nu_{t+1}}\right] \\
\theta_{L} \varepsilon_{t}^{b} \varepsilon_{t}^{L} L_{t}^{R^{\sigma}} \frac{L_{t}^{p, R}}{w_{t}}+\beta \phi E_{t}\left[\lambda_{t+1} \nu_{t+1}\left(\pi_{t+1}^{w} \nu_{t+1}-\pi\right) \pi_{t+1}^{w}{ }^{2}\right] \\
=\lambda_{t}\left[\phi \nu_{t}\left(\pi_{t}^{w} \nu_{t}-\pi\right) \pi_{t}^{w}+\left(1-\tau_{t}^{w}\right)\left(\theta_{L} L_{t}^{p, R}-L_{t}^{R}\right)\right] \\
\lambda_{t} \frac{P_{t}}{\left(1+\tau_{t}^{c}\right)}=\mu_{t}\left\{\left[1-s_{t}(.)\right]-s_{t}^{\prime}(.) \frac{\varepsilon_{t}^{i} I_{t}}{I_{t-1}} \nu_{t}\right\}+\beta E_{t}\left[\mu_{t+1} s_{t+1}^{\prime}(.) \varepsilon_{t+1}^{i}\left(\frac{I_{t+1}}{I_{t}}\right)^{2} \nu_{t+1}\right]
\end{gathered}
$$




$$
\begin{gathered}
\mu_{t}=\beta E_{t}\left\{\frac{\lambda_{t+1}}{\nu_{t+1}}\left[\left(1-\tau_{t+1}^{k}\right) R_{t+1}^{k} u_{t+1}-\psi\left(u_{t+1}\right) P_{t+1}\right]+\frac{\mu_{t+1}}{\nu_{t+1}}(1-\delta)\right\} \\
\psi^{\prime}\left(u_{t}\right) P_{t}=R_{t}^{k}\left(1-\tau_{t}^{k}\right)
\end{gathered}
$$

plus constraints (9) and (10). Defining $m c_{t} \equiv M C_{t} / Z_{t} P_{t}$ and $\chi_{t} \equiv \lambda_{t} / P_{t}$, firms' price choice f.o.c. is:

$$
\kappa\left(\widetilde{\pi}_{t}-\pi\right) \widetilde{\pi}_{t}=\beta E_{t}\left[\frac{\chi_{t+1}}{\chi_{t}} \nu_{t+1} \kappa\left(\widetilde{\pi}_{t+1}-\pi\right) \frac{1+\tau_{t}^{c}}{1+\tau_{t+1}^{c}} \widetilde{\pi}_{t+1} \frac{y_{t+1}}{y_{t}}\right]+\theta_{c} m c_{t}\left(1+\tau_{t}^{c}\right)+1-\theta_{c}
$$

First order conditions are then log-linearized around the deterministic steady state and the model is solved using linear techniques. ${ }^{17}$ We map the solution with a matrix of observables (described in the next section) and estimate the model using Bayesian inference methods, following Schorfheide (2000) and SW.

\subsection{Data and prior distributions}

We use data on private consumption, investment, real wages, inflation and nominal interest rate. As for public sector variables, we use government purchases of goods and services, transfers to households, public employment, tax rates on labor income, on capital income, on consumption and total tax revenues. In Appendix B we report sources and description of each series, we describe in detail the methodology that we have employed to compute average effective tax rates and to obtain quarterly variables from annual ones. We provide also some comparisons with alternative sources.

Real variables, except for prices and employment levels, display in the model a unit root. The corresponding observables are used in estimation in growth rates. ${ }^{18}$ Therefore the vector of observable variables $O_{t}$ is given by:

$$
O_{t}=\left[\begin{array}{c}
\Delta \log C_{t}, \Delta \log I_{t}, \Delta \log C_{t}^{g}, \Delta \log T r_{t}, \\
\Delta \log T_{t}, \Delta \log W_{t} / P_{t}, L_{t}^{g}, R_{t}, \pi_{t}, \tau_{t}^{w}, \tau_{t}^{k}, \tau_{t}^{c}
\end{array}\right]
$$

For each non stationary variable $X_{t}$ we assume an observation equation of the type:

$$
\Delta \log X_{t}=\log x_{t}-\log x_{t-1}+\log \nu_{t}
$$

\footnotetext{
${ }^{17}$ In the working paper version of the paper we reported all the steps to compute the closed form steady state and the log-linearization of the model. The current version differs only in that it assumes a unit root technology process (we did not have steady state growth in the previous version).

${ }^{18}$ We tried also to estimate the model by linearly detrending the data for government purchases and transfers (instead of using growth rates), as these variables are exogenous and modeled as autoregressive processes. Results in terms of estimated parameters are substantially unchanged.
} 
where $X_{t}$ is the real level of the observable while $x_{t}$ is the corresponding detrended variable in the model. For tax rates, we simply subtract sample means from the variables in logarithm. As for the inflation trend, we fit a linear spline until 1999:Q1 and assume a $2 \%$ target for annual inflation thereafter. The trend for the interest rate is assumed to be equal to that of the inflation rate time the steady state growth rate $\nu$ and divided by the discount factor $\beta$, consistently with the steady state of the model.

We calibrate four parameters: $\beta=0.9926$ (so that the annual steady state real interest rate is $3 \%$ ), $\delta=0.025$ (so to imply a $10 \%$ annual depreciation rate of capital), $\alpha=0.3$ (which makes the steady state labor share in income approximately equal to $70 \%$ ), $\theta_{c}=6.5$ (which implies a steady state price mark-up approximately equal to $18 \%$ ). We calibrate $\theta_{c}$ as it is difficult to jointly identify it and the adjustment cost parameter on prices $\kappa$.

Table 1 shows the main prior distributions for the remaining parameters. Prior distributions are also reported, together with posteriors, in figure 2. As for the preference parameters, a Gamma distribution is assumed for the coefficient of Frisch elasticity $\sigma_{l}$, with a mean of 3 and a standard deviation equal to 0.5 . The fraction of non-Ricardian consumers $\gamma$, whose mean is set at 0.5 as in the baseline setting in GLSV, and the habit coefficient $h$, whose mean is set at 0.7 as in SW, are distributed according to a Beta distribution with standard deviations of 0.1 . The labor wage elasticity $\theta_{L}$ is assumed to follow a Gamma distribution centered on a value of 6.5, which yields the steady state wage mark-up equal to the one for prices; a prior variance of 1 is assumed, so that - based on the priors - the markup ranges from $10 \%$ to $50 \%$ approximately.

A Gamma distribution is chosen for the four friction parameters. Since there is some uncertainty on whether prices or wages are more rigid (for example, SW claim that, despite common belief, a very robust result of their estimated model for the Euro area is the greater stickiness in prices relative to wages), we set the mean of both adjustment cost coefficients on prices and wages, $\kappa$ and $\phi$, at 100 . Given mean values for the other parameters, this assumption corresponds approximately to an adjustment frequency for prices of five quarters $^{19}$ (approximately the frequency at which the median firm changes its prices in the Euro area according to the evidence presented in Fabiani et al., 2006). The range covered by the prior distributions of both parameters is chosen so as to span approximately from less than one fifth to more than double the mean frequency of adjustment, therefore including very low degrees of nominal rigidity. Investment and capital utilization adjustment coefficients, $s^{\prime \prime}$ and $\psi^{\prime \prime} / \psi^{\prime}$, have a mean, respectively, of

\footnotetext{
${ }^{19}$ The mapping between cost of adjustment parameters and adjustment frequency can be obtained comparing coefficients in the respective expectational Phillips curves.
} 
5 and 0.2 and a standard deviation equal to 0.25 and 0.1 , in line with the priors of SW.

All non policy shocks (except for $\nu_{t}$ ) are assumed to be characterized by an $\operatorname{AR}(1)$ process of the type

$$
\log \varepsilon_{t}=\rho_{\varepsilon} \log \varepsilon_{t-1}+\eta_{t}
$$

with $\eta_{t}$ i.i.d. A Beta distribution is chosen for the autoregressive coefficients $\rho$, with mean and standard deviation set at 0.85 and 0.1 , respectively, as in SW. For these shocks, the standard deviations of the innovations are assumed to be distributed as Gamma with a 0.01 mean and 0.02 standard deviation.

Monetary policy parameters are assumed to have the same distribution type, mean and standard deviation as in SW, the only exception being that $\rho_{\pi}$, the coefficient measuring the response of the nominal rate to lagged inflation, is assumed to be Gamma rather than Normal-distributed. Innovations to monetary policy are assumed to be white noise with standard deviation distributed as Gamma with mean 0.01 and standard deviation equal to 0.02 .

Tax policies are a priori taken to be quite persistent, with autoregressive coefficients distributed as a Beta with mean 0.8 and standard deviation equal to 0.1. Tax rate elasticities with respect to debt are all assumed to be distributed as a Gamma with mean 0.5 and standard deviation equal to 0.1 (so that they range approximately between 0.2 and 0.8 ). Innovations in tax rates are assumed to be white noise with standard deviation distributed as Gamma with mean 0.01 and standard deviation equal to 0.02.

As we use data on tax rates and total tax revenues, it is unlikely that the accounting identity (16) be satisfied. We therefore added in estimation a measurement error to total revenues, $\varepsilon_{t}^{t}$, with standard deviation calibrated at $0.1 \%$. This error should capture all the other sources of revenue not covered by the three taxes considered in the model. Although in the baseline we assume this error to be i.i.d., estimation results are not substantially different if we assume that it is autocorrelated. Moreover, minor differences in results are obtained if we model $\varepsilon_{t}^{t}$ as a structural shock, instead of as a measurement error.

\section{Estimation results}

Given priors, we estimate the posterior distributions of the parameters using the Metropolis-Hastings algorithm with one million iterations, a number which seems to be sufficient to achieve convergence (as measured by the cumulated means and standard deviations of the parameters). Figure 2 plots prior and posterior distributions for a 
selection of parameters. ${ }^{20}$

Overall, most parameters seem to be well-identified, as shown by the fact that either the posterior distribution is not centered on the prior or it is centered but with a smaller dispersion. Some parameters however are not: this is the case for those related to investment adjustment cost, $s^{\prime \prime}$, the monetary response to inflation, $\rho_{\pi}$, and to a certain degree the parameters capturing the response of the consumption and capital income tax rates to the debt level. The fact that the labor income tax rate coefficient on debt is well-identified is not surprising. Labor income tax rates include social security contributions that have been increasing in the last twenty years in order to keep social security deficits under control (these deficits have been an important determinant of public debt growth in most European countries).

Right columns of table 1 summarize estimated means and standard deviations for a selection of the parameters for both the baseline specification and the model with unions representing also non-Ricardian agents. The top panel reports estimates for preference and technology parameters. The estimated fraction of non-Ricardian households (mean of the posterior) turns out to be 0.34 (0.37 with unions), which is in line with CS and below the level originally estimated by Campbell-Mankiw (1989) for the US (roughly half of the population). ${ }^{21}$

Among preference parameters, habit, $h$, and the elasticity of labor supply with respect to real wage, $1 / \sigma_{l}$, are estimated to be higher with respect to both $\mathrm{SW}$ and CS. Also the wage elasticity of labor demand, $\theta_{L}$, is estimated to be higher than the calibrated value of SW and CS, implying a lower steady state wage markup, at about $20 \%$.

With respect to both SW and CS, the estimate for price stickiness confirms the

\footnotetext{
${ }^{20}$ The percentage of accepted draws is $31 \%$. Since we initialize the MH with the estimated mode and Hessian, the latter evaluated at the mode, of the posterior distribution, we have carried out several diagnostic checks on the properties of the mode. In particular, we have checked the gradient at the mode, the conditioning number of the Hessian, the covariance among parameters implicit in the estimated Hessian. We also plotted slices of the likelihood around the mode. The Hessian is in general well conditioned and does not imply any correlation among parameters higher that 0.8 , and the likelihood at the mode shows a significant curvature for almost all parameters. This latter result, in particular, is evidence of the fact that the data contain useful information to identify the parameters.

${ }^{21}$ non-Ricardian agents can be thought of as a proxy for liquidity constrained households, whose share might have been decreasing in recent years along with the development of financial markets. We did not, however, attempt to estimate our DSGE with time varying parameters, as techniques "are still at an infant stage when it comes to structurally estimating time variations in the parameters of stochastic general equilibrium models" (Canova, 2008, pg. 4).
} 
result that it exceeds that of wages by a factor of two. Based on a Rotemberg-Calvo equivalence, price duration equals almost 7 quarters, i.e. lower than in the two above papers, though comparable with the estimate in Galí, Gertler and López-Salído (2001).

Estimated policy coefficients feature, on the monetary side, a lower smoothing and a higher weight on inflation (particularly on inflation change) with respect to both SW and CS. On the fiscal side, tax rate processes appear to be highly persistent, although the reaction to debt level is quite sizeable and large enough to be stabilizing. The autoregressive parameter for government purchases, public employment and transfers to households are estimated at respectively 0.86, 0.92 and 0.97 (levels similar to the one estimated for government consumption $G$ by both SW and CS), pointing to a high persistence of fiscal policy innovations.

As for the capacity of the model to fit the data, in figure 3 we report the crosscovariance functions of the model variables against the data. We consider four lags and four leads. We plot the 90\% confidence bands of the cross-covariance functions obtained on 10,000 random samples generated by the DSGE model. The samples are obtained by randomly drawing 100 times from the parameter posterior distribution and running the model 100 times for each parameter draw. For comparability with our data set (which is 100 period long), for each draw we run the model for 200 periods and use the first 100 as burning sample. Almost all data covariances, and in particular all those involving fiscal policy variables, fall within the confidence intervals suggesting that the model is able to mimic the cross-covariance in the data within a one year horizon.

\section{General equilibrium effects of fiscal policy}

\subsection{Government spending shocks}

We now discuss the implications of our estimates for the effects of government spending shocks on the economy. Figure 4 shows impulse responses with respect to a shock to real detrended government purchases of goods and services, figure 5 with respect to a shock to government employment, while figure 6 with respect to real detrended transfers. The solid line shows median values, while the dotted ones the 5 th and 95th percentile based on posterior distributions. The magnitude of the shocks is set in order

to have an increase in expenditures equal to one percent of steady state private output 
(i.e. excluding the government wage bill). ${ }^{22}$ Impulse responses are for each variable the deviation from steady state values expressed in percentage points. The deviations of the real interest rate and inflation (gross of consumption taxes) are reported in annualized percentage points. For the different components of revenues (from labor income, capital income and consumption taxes), total revenues and debt we report their change as a percentage of output. The bottom right panel of each figure shows the path of the shock.

We can immediately observe that on impact all three shocks increase employment and aggregate private consumption. The shock to purchases does that by increasing the demand for goods and services which, in turn, brings about an increase in employment and labor income. This sustains consumption of non-Ricardians, to an extent sufficient (also in view of their share) to compensate for the decrease in Ricardian consumption due to the negative wealth effect of debt-financed spending. Adjustments occur mainly in quantities: real wages, marginal costs, inflation and the nominal interest rate all increase mildly. The rise in employment makes the use of capital more profitable and leads to a more intensive use of capacity, while investment drops due to the increase in the rental rate of capital. ${ }^{23}$

The shock to government employment increases total labor demand and determines an increase in both total employment and labor income. However, the increase in government employment reduces the supply of labor available for private production (for any given wage) despite the increase induced by the negative wealth effect of debtfinanced government hiring. Private sector labor demand expands following the higher

\footnotetext{
${ }^{22}$ In particular, the shock to $L_{g}$ is calibrated in order to have an increase in the public wage bill, using the steady state level of wages, equal to $1 \%$ of steady state output.

${ }^{23}$ Despite a similar estimate of the mean share of non-Ricardians in their specification with (fixed) distortionary taxes, CS obtain a slightly negative response of private consumption to a government consumption $(G)$ shock. Most of the differences between our and CS results relate to the fiscal variables used in estimation and to the specification of the fiscal rules. First, as shown also by LópezSalído and Rabanal (2008) for the US, the use of data on public transfers - that translate one to one into consumption of non-Ricardians, while don't have any effect on Ricardians - is very important to identify two key parameters for the response of aggregate consumption, i.e. the share of nonRicardian agents and the habit coefficient. CS, that do not use fiscal data other than $G$, estimate an extremely low consumption habit of Ricardians (0.41; SW have 0.6), which brings about a significant fall in Ricardian consumption after the expenditure shock. Second, in order to properly identify the coefficient of the fiscal rules it is very important to use data on revenues. CS estimate an elasticity of total (lump sum) taxes to the real debt level equal to $1.5 \%$, a very high number compared to our estimate of about $0.5 \%$. Therefore, in their work total taxes increase more sharply than in our case after a deficit financed government expenditure shock, reducing on impact the disposable income of non-Ricardian households.
} 
demand for goods by non-Ricardians, which firms mostly accommodate by decreasing unitary markups on their prices. Overall, real wages and private employment increase (the latter only on impact). Labor income is higher for all households, but Ricardian consumption is depressed by the negative wealth effect. With respect to a $c_{t}^{g}$ shock, the $l_{t}^{g}$ shock has a slightly greater positive impact on private aggregate consumption, as non-Ricardian consumption hikes (after the boost in labor income), but lower on private output, as the hiring from the government tends to crowd out employment in the private sector.

Finally, the shock to transfers to households has the biggest and more persistent impact on consumption as it translates one to one into an increase in disposable income of non-Ricardians. Demand-driven output and employment also increase, while real wages are initially unchanged.

These estimated responses are consistent with a new-Keynesian framework but not with an RBC-style model. Inconsistencies with the latter lie not only in the nonnegative response of private consumption following a government expenditure shock, but also in the (mild) increase of real wages after a shock to $c_{t}^{g}$, as the wealth effect brings about an increase in labor supply that in turn should imply, in a RBC model, a decrease in the marginal productivity of labor and thus in real wages too. The increase in real wages that we find is therefore possible only if there is an outward shift in labor demand. Moreover, after a government employment shock, private employment increases on impact, although mildly, reflecting the Keynesian effect on labor demand via an increase in consumption and output. In fact, in an RBC-style model, for reasonable calibrations of the parameters, the increase in labor supply due to the standard wealth effect cannot compensate for the increased labor demand from the government, so that private sector employment would decrease on impact. The increase in private sector employment that we find is therefore due to the contemporaneous shift in labor demand. This Keynesian effect, however, does not last long and after roughly four quarters employment in the private sector starts reducing.

\subsection{Shocks to tax rates}

Next we look at the effects of tax rates innovations. Figures 7-9 plot the impulse responses of a shock to, respectively, the tax rate on labor income, capital income and consumption, all calibrated in order to achieve a decrease in revenues equal to $1 \%$ of steady state private output (that is excluding $w L^{g}$ ).

The reduction in labor income tax rate (approximately 1.6 percentage points) leads, on the one hand, to an outward shift of labor supply and, on the other hand, to 
an increase in non-Ricardian disposable income and consumption. Aggregate demand increases, and therefore output and employment also do, further reinforcing the increase in disposable income. Real wages and inflation fall. It is interesting to note that the effect of the tax cut does in fact produce on impact a revenue loss close to $1 \%$ of output: the additional revenues from the increased labor income tax base are matched by the increase in output.

The decrease in capital income tax rate (slightly less than 3 percentage points) leads on impact to a reallocation from labor to capital, whose utilization spikes up. Ricardian intertemporal choice starts favoring investment rather than consumption. The decrease in employment reduces non-Ricardian labor income. Therefore, aggregate consumption falls, and inflation do as well. Over time, however, physical capital builds up, leading employment back towards its steady state value. In the case of changes in capital income taxes, therefore, the presence of non-Ricardian consumers has a stabilizing effect on output. In fact, the expansionary effect (via an increase in capacity utilization and investment) of a reduction in $\tau_{t}^{k}$ is partially compensated by a reduction in employment and disposable income of non-Ricardians. The actual revenue loss on impact after the tax cut is higher than $1 \%$, as the reduction in the labor income tax base adds on to the reduction in capital income tax rate.

The main effect of a decrease in consumption tax rate (around 1.4 percentage points) is a one time decrease in inflation (around 5\% on annual terms) that induces a decrease in the policy and, hence, in the real interest rate. Consumption of the cheaper goods basket substantially increases, more and faster for non-Ricardians than for Ricardians. Firms increase output to meet the additional demand and they do so by increasing employment and capital utilization (investment has not become cheaper as it is not subject to consumption taxes). The smoother increase in Ricardian consumption gradually shifts resources away from investment. The actual tax revenue loss is significantly smaller than $1 \%$ : the cut in consumption taxes induces a substantial increase in labor income tax base and revenues.

Overall, the short run expansionary effect of cutting consumption taxes is greatest, while at the same time inducing a revenue loss equal to half of that measured on steady state values. Also cuts to labor income taxes have substantial positive effects on consumption and output. Capital income tax cuts, on the other hand, incur in significant revenue losses as they induce a reduction in labor income; however, as expected, the effect on output at medium term horizons is greatest. ${ }^{24}$

\footnotetext{
${ }^{24}$ Our estimated model can be used to perform dynamic scoring; see on this, among others, Mankiw and Weinzierl (2006). Although we did not analyze the issue in this paper, the evidence reported can
} 


\subsection{Fiscal multipliers}

To summarize the quantitative effects of our six fiscal shocks we report in table 2 the fiscal multipliers on private output, consumption, investment and inflation implied by our estimates. We report the average effects in the first 1, 4, 8 and 12 quarters respectively, expressed in percentage points (annualized in the case of inflation).

Fiscal multipliers on consumption and output are quite sizeable, although generally smaller than one. The average effect on output in the first year is, as expected, greatest for a shock to purchases of good and services (these being part of aggregate demand): the other shocks all have multipliers between 0.3 and 0.6. The effect on private consumption is higher for innovations to consumption taxes, labor taxes and transfers.

The impact effect on consumption and output of a reduction in labor income or consumption tax rates is similar to an increase in transfers or in public employment. The effect, in all cases, works through an increase in household (in particular nonRicardian) real labor income, which drives the increase in consumption and output. However, the innovation in public employment tends to crowd out private employment and therefore output and consumption: after 12 quarters the average effect on output and consumption becomes negative.

The effects on prices (expressed in annualized terms) are generally mild, the notable exception being innovations in consumption taxes (as they translate one to one to prices). Also increases in public employment tend to have a significant effect on nominal wages and therefore on inflation.

These results are broadly in line with available empirical evidence, coming from both VAR analyses and large-scale macroeconomic models, i.e. models which are either not microfounded at all or not in the same way as DSGEs. Analyses with VAR, though, have usually focused on a smaller set of variables than our work.

Our result of small and short-lived expansionary effects on private consumption and output following an expenditure shock is in line with the responses obtained by Mountford and Uhlig (2005) for the US and Perotti (2005) for West Germany (the only Euro area country that he considered). ${ }^{25}$ We also share with most of the VAR literature

nonetheless provide some useful information. For example, we have discussed the revenue losses of different tax cuts. Since the model is log-linear, these losses can be easily rescaled. Therefore, a cut of 1 percentage point of: i) the labor income tax rate, would lead to a revenue loss on impact of about $0.6 \%$ of GDP; ii) the capital income tax rate, of about $0.4 \%$; iii) the consumption tax rate, of about $0.35 \%$.

${ }^{25}$ Both Perotti (2005) and Mountford and Uhlig (2005) consider innovations to two variables: gov- 
the reduction of private investment in response to public consumption shock. ${ }^{26}$

As for simulation exercises run with large-scale models, they usually assume as exogenous the path of certain variables, as the interest rates or the fiscal variables themselves. This obviously complicates the comparison. Henry et al. (2004), for example, compare output and inflation responses from a selection of large-scale macro models of Euro area countries institutions with respect to four fiscal shocks: purchases of good and services, personal income tax, indirect taxes and social security contributions. The first year effect on output of a 1\% of GDP increase in purchases of goods and services ranges between 1.18 for the Deutsche Bundesbank model to 0.87 for the model of the National Bank of Belgium. The average of the models considered is 0.97, slightly higher than our number (0.85). However, the results for the second year after the shock - on the average of the countries considered - is 1.19, higher than what we find. As for the other shocks considered, we can make reasonable comparisons only with the one to indirect tax rates. ${ }^{27}$ Henry et al. (2004) report an average effect in the first year of 0.35 on GDP, not far from our estimates (0.60).

Finally, we briefly comment on the contribution of each of the structural fiscal shock to the variance of the endogenous variables (see table 3). Focusing on the long term horizon, we see that innovations to government variables have almost no explanatory power for the variance of any of the macro variables considered (except for the fiscal

ernment spending (including purchases of good and services, the public wage bill and government investment) and net taxes (i.e., taxes net of transfers to households). These definitions are different from ours and therefore any quantitative comparison with our work should take these differences into account.

${ }^{26}$ We could make a direct comparison with our estimates by running a VAR on our data. However, there are a number of difficulties in comparing DSGE and VAR. First, there is a variety of identification strategies in VARs and it is not clear which one should we compare the DSGE results with. Second and relatedly, it is very difficult to impose to the VAR the same restrictions that come from a DSGE model: there are issues of invertibility of the DSGE to obtain a VAR representation (on this see Fernandez-Villaverde, Rubio-Ramirez, Sargent and Watson, 2007), as well as problems related to the bias coming from the approximation of the VAR when working with small sample data (as discussed in Chari, Kehoe and McGrattan, 2005, Christiano, Eichenbaum and Vigfusson, 2006 and Ravenna, 2007). Third, given the number of series (12) that we use in estimation and the relatively short sample period, the large number of parameters to estimate in a VAR would reduce heavily the degrees of freedom and the precision of the estimates.

${ }^{27}$ As a matter of fact, personal income taxes include taxes on both labor and capital income, while we consider them separately. Social security contributions are, in our framework, included in $\tau^{w}$ as we assume that in the bargaining process firms care for the total cost of labor ( $w$, that includes all social security contributions) while workers do for the take-home pay $\left(w\left(1-\tau^{w}\right)\right.$, that is net of all social security contributions and personal income taxes on labor). 
variables themselves). As for the tax rates, the prominent role of technology shocks should not come as a surprise: the fiscal rules relate the tax rates to the level of debt as a share of GDP; the latter is heavily affected by technology shocks.

\subsection{Some robustness with respect to the share of non-Ricardian agents}

In figure 10 we plot the average first year response of output, consumption and investment to each of our six fiscal shocks, allowing the parameter $\gamma$ to move between 0 and 1 , while leaving the other parameters set at their estimated values. ${ }^{28}$ We focus on the share of non-Ricardians as this parameter has attracted considerable attention and it is key in determining whether the response to fiscal shocks of certain variables is positive or negative. ${ }^{29}$

Focusing on the response of private consumption to expenditures shocks, it is interesting to note that it crosses the zero line for values of $\gamma$ around 0.4 in case of innovations to purchases (note that we are here considering the average first year response, which for private consumption is lower than the impact response), while around 0.25 for innovations to public employment; it is always positive for innovation to transfers. Previous work has focused on the response of private consumption to shocks to government consumption $G$, which - based on national accounts - satisfies the identity $G=W L^{g}+C^{g}$. On average, in our sample period, the public sector wage bill has been roughly $60 \%$ of $G$. Therefore our results suggest a threshold value of $\gamma$ for a $G$ shock at about 0.3-0.35. Another interesting result is that the response of investment does not vary significantly as $\gamma$ changes (and it remains close to zero).

On the revenue side, the share of non-Ricardians has a small impact in the case of capital income and consumption tax cuts. For labor income tax shocks, the shape of the first year average responses is very similar to the one following a transfer shock and, although at a different level, that following a government employment shock. In all those cases the effects are mainly played by higher current disposable labor income

\footnotetext{
${ }^{28}$ Note that, consistently with note 17 and differently from GLSV, the equilibrium is determined over the whole range of $\gamma$.

${ }^{29}$ In the working paper version we presented an analysis with respect to a wider set of parameters. Regarding spending shocks, we noted that results are most sensitive to $\gamma$ and to the autoregressive coefficients of the expenditure processes. The effect of a greater persistence in expenditure shocks is of no surprise: as it becomes higher, the negative wealth effect on Ricardian consumption is exacerbated, and the impact response of total private consumption is diminished. Most of the other parameters have more limited effects on the results.
} 
and are therefore magnified by a higher $\gamma$. Output and private consumption tend to grow with the increase in the share of non-Ricardians following cuts to labor income and consumption tax, although in a much steeper way for labor income tax cuts.

\section{Concluding remarks}

In this paper we have presented new evidence regarding the macroeconomic effects of fiscal policy in the Euro area. To this end, we have developed a general equilibrium model and estimated its structural parameters through Bayesian techniques. As most of the Euro area official data on government accounts are available only at an annual frequency and given the importance for our purposes of including detailed information on government variables, we have also computed quarterly data for important fiscal policy series.

Our results point to a significant share of non-Ricardian agents and to the prevalence of mild Keynesian effects of fiscal policy. In particular, although innovations in fiscal policy variables tend to be rather persistent, government purchases of goods and services and compensations for public employees have small and short lived expansionary effects on private consumption, while innovations to transfers to households show a slightly more sizeable and lasting effect. The effects are more significant on the revenue side: decreases in labor income and consumption tax rates have sizeable effects on consumption and output, while a reduction in capital income tax favors investment and output in the medium run. Moreover, our results suggest that fiscal policy variables contribute little to the cyclical variability of the main macro variables.

The reported evidence seems to favor the new-Keynesian framework. The estimated impact increases in private aggregate consumption and real wages after shocks to government spending items, and in private sector employment after a government employment shock, are not consistent with standard RBC models.

While our model is rather general, we have restricted our focus to a closed economy setup. Although we believe this is a good approximation for an economic area as the Euro area, as SW have shown, we might still be missing some effects coming from the external channel. This, however, is a topic for future research. 


\section{References}

Alesina A., S. Ardagna, R. Perotti and F. Schiantarelli (2002), Fiscal Policy, Profits, and Investment, American Economic Review, Vol. 92, No. 3.

Adolfson M., S. Laseen, J. Linde and M. Villani (2007), Bayesian Estimation of an Open Economy DSGE Model with Incomplete Pass-Through, Journal of International Economics, forthcoming.

Barbone L., G. Bodo and I. Visco (1981), Costi e profitti nell'industria in senso stretto: un'analisi su serie trimestrali, 1970-1980, Bank of Italy Economic Bulletin, No. 36.

Baxter M. and R.G. King (1993), Fiscal Policy in General Equilibrium, American Economic Review, Vol. 83, No. 3.

Bilbiie F. (2006), Limited Asset Market Participation, Monetary Policy and (Inverted) Keynesian Logic, mimeo.

Blanchard O. (1985), Debt, Deficits, and Finite Horizons, Journal of Political Economy, Vol. 93, No. 2.

Blanchard O. and R. Perotti (2002), An Empirical Characterization of the Dynamic Effects of Changes in Government Spending and Taxes on Output, Quarterly Journal of Economics, Vol. 117, No. 4.

Campbell J.Y. and G. Mankiw (1989), Consumption, Income and Interest Rate: Reinterpreting the Time Series Evidence, in O.J. Blanchard and S. Fisher eds., NBER Macroeconomics Annual 1989, MIT Press.

Canova F. (2008), How much Structure in Empirical Models?, Palgrave Handbook of Economics, Vol. 2, Applied Econometrics.

Carey D. and J. Rabesona (2002), Tax Ratios on Labour and Capital Income and Consumption, OECD Economic Studies, Vol. 35, No. 2.

Cavallo M. (2007), Government Consumption Expenditures and the Current Account, Public Finance and Management, Vol. 7, No. 1.

Chari V.V., P. Kehoe and E. McGrattan (2005), A Critique of Structural VARs using Business Cycle Theory, Federal Reserve Bank of Minneapolis Staff Report 364. 
Chari V.V., P. Kehoe and E. McGrattan (2005), New Keynesian Models: Not yet Useful for Policy Analysis, NBER working paper No. 14313.

Chow G.C. and A.L. Lin (1971), Best Linear Unbiased Interpolation, Distribution, and Extrapolation of Time Series by Related Series, The Review of Economics and Statistics, Vol. 53.

Christiano L.J., M. Eichenbaum and L.E. Evans (2005), Nominal Rigidities and the Dynamic Effect of a Shock to Monetary Policy, Journal of Political Economy, Vol. 113, No. 1.

Christiano L.J., M. Eichenbaum and R. Vigfusson (2006), Assessing Structural VARs, International Finance Discussion Papers 866, Board of Governors of the Federal Reserve System.

Coenen G. and R. Straub (2005), Does Government Spending Crowd in Private Consumption? Theory and Empirical Evidence for the Euro Area, International Finance, Vol. 8.

Coenen G., P. McAdam and R. Straub (2008), Tax Reform and Labour-Market Performance in the Euro Area: A Simulation-Based Analysis Using the New Area-Wide Model, Journal of Economic Dynamics and Control, Vol. 32, No. 8.

Colciago A. (2006), Sticky Wages and Rule-of-Thumb Consumers, mimeo.

De Bandt O. and F.P. Mongelli (2002), Convergence of Fiscal Policies in the Euro Area, Chapter 4 in M. Buti, J. Von Hagen and C. Martinez-Mongay (eds.), The Behavior of Fiscal Authorities, Palgrave.

Erceg C.J., L. Guerrieri and C. Gust (2005), Expansionary Fiscal Shocks and the Trade Deficit, International Finance, Vol. 8, No. 3.

Eurostat (2007), Taxation Trends in the European Union.

Fabiani S., M. Druant, I. Hernando, C. Kwapil, B. Landau, C. Loupias, F. Martins, T.Y. Matha, R. Sabbatini, H. Stahl and C.J. Stockman (2006), What Firms' Surveys Tell Us about Price-Setting Behavior in the Euro Area, International Journal of Central Banking, Vol. 2, No. 3.

Fernandez-Villaverde J. and J.F. Rubio-Ramirez (2004), Comparing dynamic equilibrium models to data: a Bayesian approach, Journal of Econometrics, Vol. 123. 
Fernandez-Villaverde J. and J.F. Rubio-Ramirez (2006), Our research agenda: estimating DSGE models, newsletter of the Review of Economic Dynamics, fall 2006.

Fernandez-Villaverde J., J.F. Rubio-Ramirez, T.J. Sargent and M. Watson (2007), A,B,C's (and D's) for Understanding VARs, American Economic Review, Vol. 97.

Finn M.G. (1998), Cyclical Effects of Government Employment and Goods Purchases, International Economic Review, Vol. 39, No. 3.

Forni L. and S. Momigliano (2004), Cyclical Sensitivity of Fiscal Policies based on Real Time Data, Applied Economics Quarterly, Vol. 50, No. 3.

Forni L., A. Gerali and M. Pisani (2008), The Macroeconomics of Fiscal Consolidation in a Monetary Union: the Case of Italy, mimeo Bank of Italy (see http://www.lforni.it/ResearchAndPublications/Publications.htm).

Forni L., L. Monteforte and L. Sessa (2007), The General Equilibrium Effects of Fiscal Policy: Estimates for the Euro Area, Bank of Italy Working Paper No. 652.

Furlanetto F. (2006), Fiscal Shocks and the Consumption Response when Wages are Sticky, mimeo.

Galí J., M. Gertler and J.D. López-Salído (2001), European Inflation Dynamics, European Economic Review, Vol. 45.

Galí J., J.D. López-Salído and J. Vallés (2007), Understanding the Effects of Government Spending on Consumption, Journal of the European Economic Association, Vol. 5, No. 1.

Galí J., J.D. López-Salído and J. Vallés (2004), Rule-of-Thumb Consumers and the Design of Interest Rate Rules, Journal of Money, Credit and Banking, Vol. 36.

Galí J. and R. Perotti (2003), Fiscal Policy and Monetary Integration in Europe, Economic Policy, Vol. 37.

Goodfriend M. and R.J. King (1997), The New Neoclassical Synthesis and the Role of Monetary Policy, NBER Macroeconomics Annual.

Henry J., P. Hernandez de Cos and S. Momigliano (2004), The Short Term Impact of Government Budgets on Prices: Evidence from Macroeconomic Models, ECB Working Paper No. 396. 
Kim J. (2000), Constructing and Estimating a Realistic Optimizing Model of Monetary Policy, Journal of Monetary Economics Vol. 45.

Linnemann L. and A. Schabert (2003), Fiscal Policy in the New Neoclassical Synthesis, Journal of Money, Credit, and Banking, Vol. 35, No. 6.

López-Salído J.D. and P. Rabanal (2008), Government Spending and ConsumptionHours Preferences, mimeo.

Mankiw N.G. (2000), The Savers-Spenders Theory of Fiscal Policy, American Economic Review, Vol. 90, No. 2.

Mankiw N.G. and M. Weinzierl (2006), Dynamic Scoring: a back-of-the-envelope Guide, Journal of Public Economics, Vol. 90.

Marcellino M. (2006), Some Stylized Facts on Fiscal Policy in the Euro Area, Journal of Macroeconomics, Vol. 28.

Mendoza E.G., A. Razin and L.L. Tesar (1994), Effective Tax Rates in Macroeconomics: Cross-country Estimates of Tax Rates on Factor Incomes and Consumption, Journal of Monetary Economics, Vol. 34, No. 3.

Mountford A. and H. Uhlig (2005), What are the Effects of Fiscal Policy Shocks?, SFB 649 Discussion Paper.

Pappa E. (2005), New-Keynesian or RCB Transmission? The Effects of Fiscal Shocks in Labor Markets, CEPR Discussion Paper n. 5313.

Perotti R. (2007), In search of the Transmission Mechanism of Fiscal Policy, NBER Macroeconomics Annual $200 \%$.

Perotti R. (2005), Estimating the Effects of Fiscal Policy in OECD Countries, CEPR Discussion Paper No. 4842.

Ramey V.A. (2008): Identifying Government Spending Shocks: It's All in the Timing, mimeo UCDSD.

Ravenna F. (2007), Vector Autoregressions and Reduced Form Representations of DSGE models, Journal of Monetary Economics, 54.

Romanov A. (2003), International Effects of Fiscal Policies, mimeo IMF. 
Rotemberg J.J. and M. Woodford (1992): Oligopolistic Pricing and the Effects of Aggregate Demand on Economic Activity, Journal of Political Economy, Vol. 100, No. 6.

Sala L. (2004), The Fiscal Theory of the Price Level: Identifying Restrictions and Empirical Evidence, IGIER Working Paper No. 257.

Schorfheide F. (2000), Loss Function-Based Evaluation of DSGE Models, Journal of Applied Econometrics, Vol. 15.

Schmitt-Grohé S. and M. Uribe (2006), Optimal Fiscal and Monetary Policy in a Medium-Scale Macroeconomic Model, NBER Macroeconomics Annual 2005.

Smets F. and R. Wouters (2003), An estimated Dynamic Stochastic General Equilibrium Model of the Euro area, Journal of the European Economic Association, Vol. 1, No. 5.

van den Noord P. (2000), The Size and Role of Automatic Fiscal Stabilizers in the 1990s and Beyond, OECD Economics Department WP, No. 230.

\section{Appendix}

\section{A An alternative specification for the labor market}

The way labor supply of non-Ricardian agents reacts to fiscal shocks is key to the dynamic responses in our model. In fact, as we assume that non-Ricardian behavior in the labor market fully mirrors Ricardian behavior, the labor supply increase of the latter due to negative wealth effects is entirely transmitted to non-Ricardian agents. Following a government spending shock, such spillover could induce an upward bias in the responses of aggregate labor supply, labor income (given sticky wages) and, ultimately, both non-Ricardian and aggregate consumption. In order to control this potential bias we consider an alternative labor market structure which tries to give an explicit role to non-Ricardian agents in labor choices. In this alternative structure each worker delegates the intertemporal wage choice to a union whose preferences equally represent those of all agents in the economy. Our modeling extends the union setup proposed by GLSV to include the presence of (intertemporal) wage adjustment costs.

We consider a continuum of labor types, which are employed both in the private and in the public sector, and one union for each labor type $m$. Each union represents $1-\gamma$ Ricardians and $\gamma$ non-Ricardians (all indexed by $i$, perfectly substitutable in 
work effort within their own labor type $m$ ). The typical union $m$ sets nominal wages $\left\{w_{t}(m)\right\}_{t=0}^{\infty}$ for workers of its labor type subject to quadratic adjustment costs and to demand schedules in the private and the public sector (the latter following the exogenous process specified in the main text). The union equally charges each member household with lump-sum fees to cover wage adjustment costs. It trades off the utility value of intertemporal labor income gains from working in either sector (net of both wage adjustment costs and taxes) versus the disutility of the work effort. That is, it maximizes:

$$
\begin{gathered}
E_{0} \sum_{t=0}^{\infty} \beta^{t}\left\{\gamma\left[U_{c_{t}^{N R}(i, m)}\left(\left(1-\tau_{t}^{w}\right) \frac{w_{t}(m)}{P_{t}} L_{t}^{N R}(i, m)-\frac{\phi}{2}\left(\frac{w_{t}(m)}{w_{t-1}(m)} \nu_{t}-\pi\right)^{2} \frac{w_{t}}{P_{t}}\right)-\frac{\varepsilon^{b} \varepsilon^{L} L_{t}^{N R}(i, m)^{1+\sigma_{L}}}{1+\sigma_{L}}\right]\right. \\
\quad+(1-\gamma)\left[U_{c_{t}^{R}(i, m)}\left(\left(1-\tau_{t}^{w}\right) \frac{w_{t}(m)}{P_{t}} L_{t}^{R}(i, m)-\frac{\phi}{2}\left(\frac{w_{t}(m)}{w_{t-1}(m)} \nu_{t}-\pi\right)^{2} \frac{w_{t}}{P_{t}}\right)-\frac{\varepsilon^{b} \varepsilon^{L} L_{t}^{R}(i, m)^{1+\sigma_{L}}}{1+\sigma_{L}}\right]
\end{gathered}
$$

subject to (for $T=\{R, N R\})$

$$
\begin{gathered}
L_{t}^{T}(i, m)=L_{t}^{p, T}(i, m)+L_{t}^{g, T}(i, m) \\
L_{t}^{g, T}(i, m)=L_{t}^{g}(i, m)=L_{t}^{g}(m) \\
L_{t}^{p, T}(i, m)=L_{t}^{p}(i, m)=L_{t}^{p}(m)=\left(\frac{w_{t}(m)}{w_{t}}\right)^{-\theta_{L}} L_{t}^{p}
\end{gathered}
$$

where constraints recognize that the union takes into account that firms and the public sector allocate labor demand uniformly across different workers of type $m$, independently of them being Ricardian or non-Ricardian.

Assuming that all households have external habits which are group-specific, with a common habit parameter $h$, in a symmetric equilibrium the first order condition reads

$$
\begin{aligned}
& {\left[\frac{\gamma \varepsilon_{t}^{b}}{\left(c_{t}^{N R}-h \frac{c_{t-1}^{N R}}{\nu_{t}}\right)}+\frac{(1-\gamma) \varepsilon_{t}^{b}}{\left(c_{t}^{R}-h \frac{c_{t-1}^{R}}{\nu_{t}}\right)}\right]\left[\phi_{w}\left(\pi_{t}^{w} \nu_{t}-\pi\right) \pi_{t}^{w} \nu_{t}+\left(1-\tau_{t}^{w}\right)\left(\theta_{L} L_{t}^{p}-L_{t}\right)\right] } \\
= & \theta_{L} \varepsilon_{t}^{b} \varepsilon_{t}^{L} \frac{L_{t}^{p}}{\omega_{t}} L_{t}^{\sigma_{L}}+\phi \beta E_{t}\left\{\left[\frac{\gamma \varepsilon_{t+1}^{b}}{\left(c_{t+1}^{N R}-h \frac{c_{t}^{N R}}{\nu_{t}+1}\right)}+\frac{(1-\gamma) \varepsilon_{t+1}^{b}}{\left(c_{t+1}^{R}-h \frac{c_{t}^{R}}{\nu_{t+1}}\right)}\right]\left(\pi_{t+1}^{w} \nu_{t+1}-\pi\right) \frac{\pi_{t+1}^{w^{2}}}{\pi_{t+1}} \nu_{t+1}\right\}
\end{aligned}
$$

which for $\gamma=0$ reduces to the analogous equation of the baseline specification, where it is only Ricardian households who choose the wage. For $\gamma \neq 0$, discounting is done through a weighted average of the marginal utilities of the two types of agents in the economy. 
The last two columns of table 1 report the posterior parameter distributions obtained estimating the model with this version of the labor market, while leaving all other aspects unchanged. Most parameters values are only marginally changed. In particular the share of non-Ricardian agents, $\gamma$, is now estimated (mean of the posterior) at 0.37 , instead of 0.34 as in the baseline. Therefore, including non-Ricardian agents in the wage optimization problem, weighted by their share, increases only marginally the estimated share of non-Ricardians. The other parameter that is affected by the different assumptions regarding the labor market is the wage elasticity of the labor demand, $\theta_{L}$, now estimated at 5.8 instead of 6.2 . That implies that the steady state wage markup increases slightly, from 19 to 20\%. The dynamic behavior of the model is in every respect very similar to the baseline case.

\section{B Data sources and description}

\section{B.1 General description}

The model is estimated using quarterly data over the period from 1980:1 to 2005:4. The National Accounts (NA) and the government sector series are seasonally adjusted and, when available, working day adjusted.

Data for quarterly NA variables (household consumption, capital accumulation, private compensations and public employment) are taken from the Eurostat ESA95 data base. Euro area NA data have a break in 1991 because of the German unification: for previous years, we use the series reconstructed by the ECB for the Area Wide Model (AWM-ECB)..$^{30}$

A large part of the Euro area information for the government sector is available only on annual basis. ${ }^{31}$ Annual fiscal data for $C^{g}, T$ and $T r$ are mainly obtained from the AMECO data base of the European Commission. ${ }^{32}$ Considering breaks in accounting standards as well as German unification, we had to join ESA79 (excluding East Germany) with ESA95 series in order to obtain series starting from 1980. In each of these joins, we removed level discontinuities by applying the growth rates of the old series to the levels of the new series, as done by most data providers. We then obtained

\footnotetext{
${ }^{30}$ In particular we refer to the release of the AWM-ECB updated to the 2005:4, available on the web site of the Euro Area Business Cycle Network-EABCN.

${ }^{31}$ Recently Eurostat has released a number of quarterly series for the principal items of the government accounts, but only for a short time span (from 1999:1) and not adjusted either for seasonality or for working days.

${ }^{32}$ In alternative to AMECO some variables, as documented in the following section, are extracted from ECOUT, the data base of the OECD Economic Outlook.
} 
quarterly series from annual ones, applying standard techniques commonly adopted by national statistical offices to estimate high frequency series using proxy indicators. In particular, we followed the Chow and Lin (1971) method, as modified by Barbone et al. (1981). We used a particular care in the choice of the quarterly NA indicators for each series.

Concerning implicit tax rates we computed annual series starting from 1980 following the original contribution by Mendoza et al. (1994, henceforth MRT). In their original paper, the series were computed for the period 1965-1988 and, among Euro area countries, only for Germany, France and Italy. We obtained our annual rates applying the same formulas as MRT to Euro area data. To compute the quarterly rates, we had to pick quarterly NA indicators for each variable entering in the computation of the rate, as detailed in the next section.

\section{B.2 Data sources and methodology for the individual data series}

In the following we document, series by series, the sources and the data processing that we have done.

Households' consumption $(C)=$ real private consumption; source: AWM-ECB data set up to 1990:4 and NA-ESA95 thereafter.

Investment $(I)=$ real investments; source: AWM-ECB up to 1990:4 and NA-ESA95 thereafter.

Interest rate $(R)=$ three-months nominal interest rate; source: AWM-ECB.

Inflation rate $(\pi)=$ annual percentage changes of the Harmonized Index of Consumer Price (HICP); source: AWM-ECB.

Private per-capita real compensations $(W / P)=$ private sector per-capita real compensations, computed as the ratio between private compensations and private employees (private variables are computed as difference between whole economy and public sector values); source: AWM-ECB up to 1990:4 and NA-ESA95 thereafter.

Government consumption less compensations $\left(C^{g}\right)=$ real government purchases of good and services (does not include any type of transfers); source for annual series: ECOUT. The quarterly indicator is the difference between government consumption and non-market compensations; source for the quarterly indicator: AWM-ECB up to 1990:4 and NA-ESA95 thereafter.

Government transfers $(\mathrm{Tr})=$ real government transfers to households; source for annual series: AMECO. The quarterly indicator is the unemployment rate.

Total revenues $(T)=$ real government total revenues; source for annual nominal series: AMECO. The quarterly indicator is a sum of three components: 1) a series of 
direct taxes, with the annual data from AMECO and the quarterly data reconstructed using as indicator the NA data on value added in the market sector; 2) a series of indirect taxes, with the annual data from AMECO and the quarterly data reconstructed using as indicator the NA data on private and public consumption; 3) a series of social contributions, with the annual data from AMECO and the quarterly data reconstructed using as indicator the NA data for social contributions.

Government employment $\left(L^{g}\right)=$ public employees; source: ECOUT.

Tax rate on labor income $\left(\tau^{w}\right)=$ the series is computed in two steps: 1) an average direct tax rate $(t h h)$ is computed as:

$$
t h h=\frac{T D_{h}}{(O S P U E+P E I+W)}
$$

2) the labor tax rate is given by

$$
\tau^{w}=\frac{\left(\operatorname{thh} W+S C+T_{w}\right)}{\left(W+S C_{e}\right)}
$$

where:

$T D_{h}=$ households direct taxes

$O S P U E=$ operating surplus of private unincorporated firms

$P E I=$ household property and entrepreneurial income

$W=$ wages

$S C=$ social contributions

$T_{w}=$ taxes on payroll and workforce

$S C_{e}=$ employers social contributions

$\tau^{w}$ is therefore a measure of the share of labor taxes and social contributions (the numerator) on the labor cost (the denominator). Sources for the annual series: OECD Revenue Statistics and AMECO. As quarterly indicators, we use for $T D_{h}$ the NA data on value added in the market sector, while for $O S P U E+P E I$ the NA profit series. For wages and social contributions quarterly NA series are available.

Tax rate on consumption $\left(\tau^{c}\right)=$ the series is given by the ratio

$$
\tau^{c}=\frac{T I_{1}+T I_{2}}{\left(C+C^{g}-T I_{1}-T I_{2}\right)}
$$

where:

$T I_{1}=$ general taxes on goods and services

$T I_{2}=$ excise taxes

$\tau^{c}$ is therefore the tax rate on private and public consumption. Sources for the annual 
series: OECD Revenue Statistics, AMECO and ECOUT. As quarterly indicator for $T I_{1}$ and $T I_{2}$ we use the NA quarterly data on private and public consumption.

Tax rate on capital income $\left(\tau^{k}\right)=$ the series is computed as follows:

$$
\tau^{k}=\frac{\left(t h h(O S P U E+P E I)+T D_{k}+T P+T T R\right)}{N O S}
$$

where thh is defined in (30) and:

$T D_{k}=$ direct taxes on corporations

$N O S=$ net operating surplus of the economy

$T P=$ taxes on immovable property

$T T R=$ taxes on financial and capital transactions

$\tau^{k}$ is therefore a measure of how taxes on all kind of businesses (the numerator) affect profits (the denominator). Sources for annual series: OECD Revenue Statistics and AMECO. As quarterly indicators, we use for $T D_{k}$ the NA data on value added in the market sector, while for NOS the NA profit series. Given the lack of suitable quarterly indicators for both $T P$ and $T T R$, these series are made quarterly by using a linear trend.

\section{B.3 Comparison of our tax rates with alternative sources}

Although coverage and definitions are slightly different, we can compare our tax rates series with those of three alternative data sets. Eurostat provides official yearly tax rate series starting from 1995, using a modified version of the MRT methodology. This latter is also at the basis of the OECD paper by Carey and Rabesona (2002, henceforth CR), where time series for OECD countries covering the years 1975-2000 are presented.

Our rates are an updated version for the Euro area of the rates computed by MRT. On an annual basis they can be compared with those provided by Eurostat as well as with those in MRT and in CR, all based on the MRT methodology: while CR introduce some modifications, Eurostat complements its calculations using country data not always in the public domain.

In terms of coverage, among Euro area countries MRT computed rates from 1965 to 1988 only for Germany, France and Italy. CR have longer series (from 1975 to 2002) for seven countries in the Euro area. ${ }^{33}$ To compute figures for the Euro area, we aggregated these national rates using fixed GDP weights. Eurostat has computed tax rates for each European country since 1995 and provides GDP-weighted series.

\footnotetext{
${ }^{33}$ The countries are Germany, France, Italy, Austria, Belgium, Finland and Spain. The series in CR are from 1980 to 2000, but in this appendix we refer to an update version up to 2002, kindly provided by the authors.
} 
The top panel in figure 1 shows labor income tax rates. Our series is the highest but is comparable with MRT. The central panel of the figure shows that our tax rates on consumption closely track the MRT one in the first part of the eighties and almost overlaps with that of CR thereafter. The difference with the Eurostat series is mainly due to the fact that Eurostat does not include government purchases of goods and services in the tax base. Finally, in the bottom panel we report capital income tax rates.

Overall our estimates are higher than alternative figures for labor income tax rates, while lower than those for capital income. The difference relates mainly to the way direct taxes are split between labor and capital income revenues: in this we follow the MRT methodology (and in fact our series are close to theirs), while Eurostat uses additional information and $\mathrm{CR}$ introduce some modifications in the MRT methodology. However, as we use the demeaned series in estimation, we are mainly concerned with the profile of the rates (which is similar across different sources) more than with their levels. 
Table 1: Selected prior and posterior distributions

\begin{tabular}{|c|c|c|c|c|c|c|c|}
\hline \multirow[t]{3}{*}{ Parameter } & \multirow{2}{*}{\multicolumn{3}{|c|}{ Prior distrib. }} & \multicolumn{4}{|c|}{ Posterior } \\
\hline & & & & \multicolumn{2}{|c|}{ Baseline } & \multicolumn{2}{|c|}{ Unions } \\
\hline & Type & Mean & St.Dev. & Mean & St.Dev. & Mean & St.Dev. \\
\hline \multicolumn{8}{|l|}{ Preferences and technology } \\
\hline inv. lab. supply wage elast. $\sigma_{L}$ & $\Gamma$ & 3 & 0.5 & 2.00 & 0.25 & 1.94 & 0.23 \\
\hline fraction of non-Ricardians $\gamma$ & $\beta$ & 0.5 & 0.1 & 0.34 & 0.03 & 0.37 & 0.02 \\
\hline habit parameter & $\beta$ & 0.7 & 0.1 & 0.73 & 0.03 & 0.72 & 0.02 \\
\hline labor demand wage elast. $\quad \theta_{L}$ & $\Gamma$ & 6.5 & 1 & 6.20 & 0.73 & 5.84 & 0.66 \\
\hline \multicolumn{8}{|l|}{ Frictions } \\
\hline investment adj. cost & $\Gamma$ & 5 & 0.25 & 5.30 & 0.25 & 5.27 & 0.25 \\
\hline wage adjustment cost & $\Gamma$ & 100 & $1000^{\frac{1}{2}}$ & 109.45 & 28.08 & 80.41 & 20.55 \\
\hline price adjustment cost & $\Gamma$ & 100 & $1000^{\frac{1}{2}}$ & 214.60 & 21.53 & 204.86 & 29.78 \\
\hline capital utilization cost $\psi^{\prime \prime} / \psi^{\prime}$ & $\Gamma$ & 0.2 & 0.1 & 0.22 & 0.03 & 0.28 & 0.06 \\
\hline \multicolumn{8}{|l|}{ Monetary policy } \\
\hline interest rate $\mathrm{AR}$ coeff. & $\beta$ & 0.8 & 0.1 & 0.92 & 0.01 & 0.91 & 0.01 \\
\hline inflation coefficient & $\Gamma$ & 1.7 & 0.1 & 1.72 & 0.10 & 1.73 & 0.10 \\
\hline output coefficient & $\mathrm{N}$ & 0.125 & 0.05 & 0.13 & 0.03 & 0.08 & 0.02 \\
\hline inflation change coeff. & $\mathrm{N}$ & 0.3 & 0.1 & 0.23 & 0.09 & 0.25 & 0.09 \\
\hline output growth coeff. & $\mathrm{N}$ & $0.25^{2}$ & 0.05 & 0.07 & 0.01 & 0.05 & 0.01 \\
\hline \multicolumn{8}{|l|}{ Fiscal policy } \\
\hline labor tax rate $\mathrm{AR}$ coeff. $\quad \rho_{\tau^{w}}$ & $\beta$ & 0.8 & 0.1 & 0.91 & 0.01 & 0.89 & 0.01 \\
\hline labor tax rate debt coeff. $\eta_{\tau^{w}}$ & $\Gamma$ & 0.5 & 0.1 & 0.28 & 0.03 & 0.27 & 0.03 \\
\hline cons. tax rate AR coeff. $\quad \rho_{\tau^{c}}$ & $\beta$ & 0.8 & 0.1 & 0.96 & 0.00 & 0.95 & 0.01 \\
\hline cons. tax rate debt coeff. $\quad \eta_{\tau^{c}}$ & $\Gamma$ & 0.5 & 0.1 & 0.50 & 0.06 & 0.47 & 0.05 \\
\hline capital tax rate $\mathrm{AR}$ coeff. $\rho_{\tau^{k}}$ & $\beta$ & 0.8 & 0.1 & 0.97 & 0.00 & 0.96 & 0.01 \\
\hline capital tax rate debt coeff. $\eta_{\tau^{k}}$ & $\Gamma$ & 0.5 & 0.1 & 0.57 & 0.06 & 0.46 & 0.06 \\
\hline \multicolumn{4}{|l|}{ Loglikelihood } & \multicolumn{2}{|c|}{-4750.2} & \multicolumn{2}{|c|}{-4753.3} \\
\hline
\end{tabular}


Table 2: Fiscal multipliers

\begin{tabular}{|c|c|c|c|c|c|c|}
\hline & & Quarters & $\frac{\Delta y}{y}$ & $\frac{\Delta c}{c}$ & $\frac{\Delta I}{I}$ & $\Delta \pi$ \\
\hline \multirow[t]{12}{*}{ Increase in } & \multirow[t]{4}{*}{$c^{g}$} & 1 & 1.21 & 0.05 & -0.04 & 0.21 \\
\hline & & 4 & 0.85 & -0.03 & -0.07 & 0.20 \\
\hline & & 8 & 0.54 & -0.09 & -0.10 & 0.20 \\
\hline & & 12 & 0.35 & -0.11 & -0.11 & 0.19 \\
\hline & \multirow[t]{4}{*}{$L^{g}$} & 1 & 0.33 & 0.22 & 0.03 & 1.14 \\
\hline & & 4 & 0.27 & 0.15 & 0.02 & 1.11 \\
\hline & & 8 & 0.07 & 0.01 & -0.02 & 1.04 \\
\hline & & 12 & -0.14 & -0.11 & -0.07 & 0.99 \\
\hline & \multirow[t]{4}{*}{ tr } & 1 & 0.42 & 0.35 & 0.00 & 0.30 \\
\hline & & 4 & 0.31 & 0.27 & 0.00 & 0.30 \\
\hline & & 8 & 0.21 & 0.19 & -0.01 & 0.30 \\
\hline & & 12 & 0.12 & 0.12 & -0.02 & 0.30 \\
\hline \multirow[t]{12}{*}{ Reduction of } & \multirow[t]{4}{*}{$\tau^{w}$} & 1 & 0.39 & 0.34 & 0.00 & -0.11 \\
\hline & & 4 & 0.31 & 0.28 & 0.02 & -0.08 \\
\hline & & 8 & 0.26 & 0.22 & 0.04 & -0.03 \\
\hline & & 12 & 0.23 & 0.18 & 0.06 & 0.02 \\
\hline & \multirow[t]{4}{*}{$\tau^{k}$} & 1 & 0.33 & -0.14 & 0.04 & -0.72 \\
\hline & & 4 & 0.35 & -0.17 & 0.11 & -0.58 \\
\hline & & 8 & 0.45 & -0.16 & 0.20 & -0.41 \\
\hline & & 12 & 0.52 & -0.14 & 0.26 & -0.29 \\
\hline & \multirow[t]{4}{*}{$\tau^{c}$} & 1 & 0.53 & 0.36 & -0.05 & -5.01 \\
\hline & & 4 & 0.60 & 0.49 & -0.11 & -1.33 \\
\hline & & 8 & 0.58 & 0.53 & -0.19 & -0.68 \\
\hline & & 12 & 0.51 & 0.52 & -0.24 & -0.46 \\
\hline
\end{tabular}

Note: Fiscal multipliers are computed as averages of the percent responses over the specified number of quarters. Expenditure innovations are set equal to $1 \%$ of steady state output. Tax rates innovations are such that the reduction of revenues is equal to $1 \%$ of steady state output. The change in inflation is expressed in annualized percentage points. 
Table 3: Variance decomposition

\begin{tabular}{|c|c|c|c|c|c|c|c|c|c|c|c|c|c|c|}
\hline \multicolumn{15}{|c|}{ after 1 period } \\
\hline & $\varepsilon^{z}$ & $\varepsilon^{\nu}$ & $\varepsilon^{b}$ & $\varepsilon^{L}$ & $\varepsilon^{m}$ & $\varepsilon^{c g}$ & $\varepsilon^{t r}$ & $\varepsilon^{\tau w}$ & $\varepsilon^{\tau c}$ & $\varepsilon^{\tau k}$ & $\varepsilon^{i}$ & $\varepsilon^{l g}$ & $\varepsilon^{t}$ & Tot \\
\hline$\Delta \log C$ & 0.5 & 6.5 & 82.4 & 2.4 & 6.7 & 0.0 & 0.1 & 1.1 & 0.2 & 0.0 & 0.0 & 0.0 & 0.0 & 100 \\
\hline$\Delta \log I$ & 0.1 & 10.9 & 9.1 & 0.5 & 4.7 & 0.0 & 0.0 & 0.0 & 0.0 & 0.0 & 74.7 & 0.0 & 0.0 & 100 \\
\hline$\pi$ & 34.6 & 17.3 & 7.8 & 21.4 & 1.8 & 0.1 & 0.0 & 0.0 & 16.3 & 0.3 & 0.0 & 0.2 & 0.0 & 100 \\
\hline$R$ & 6.4 & 4.0 & 13.6 & 6.4 & 65.0 & 0.9 & 0.0 & 0.1 & 1.2 & 0.0 & 2.4 & 0.0 & 0.0 & 100 \\
\hline$\tau^{w}$ & 0.0 & 0.0 & 0.1 & 0.0 & 0.0 & 0.0 & 0.0 & 99.9 & 0.0 & 0.0 & 0.0 & 0.0 & 0.0 & 100 \\
\hline$\tau^{c}$ & 0.0 & 0.0 & 0.0 & 0.0 & 0.0 & 0.0 & 0.0 & 0.0 & 99.9 & 0.0 & 0.0 & 0.0 & 0.0 & 100 \\
\hline$\tau^{k}$ & 0.0 & 0.0 & 0.0 & 0.0 & 0.0 & 0.0 & 0.0 & 0.0 & 0.0 & 100 & 0.0 & 0.0 & 0.0 & 100 \\
\hline$\Delta \log \frac{W}{P}$ & 0.0 & 0.9 & 4.1 & 93.2 & 0.8 & 0.0 & 0.0 & 0.1 & 0.9 & 0.0 & 0.0 & 0.0 & 0.0 & 100 \\
\hline$\Delta \log T$ & 3.8 & 3.6 & 31.3 & 21.2 & 5.6 & 2.3 & 0.0 & 10.0 & 0.2 & 2.1 & 3.4 & 0.3 & 16.3 & 100 \\
\hline \multicolumn{15}{|c|}{ after 4 periods } \\
\hline & $\varepsilon^{z}$ & $\varepsilon^{\nu}$ & $\varepsilon^{b}$ & $\varepsilon^{L}$ & $\varepsilon^{m}$ & $\varepsilon^{c g}$ & $\varepsilon^{t r}$ & $\varepsilon^{\tau w}$ & $\varepsilon^{\tau c}$ & $\varepsilon^{\tau k}$ & $\varepsilon^{i}$ & $\varepsilon^{l g}$ & $\varepsilon^{t}$ & Tot \\
\hline$\Delta \log C$ & 1.2 & 9.4 & 79.3 & 2.7 & 6.1 & 0.0 & 0.1 & 1.0 & 0.2 & 0.0 & 0.0 & 0.0 & 0.0 & 100 \\
\hline$\Delta \log I$ & 0.7 & 11.0 & 11.7 & 0.9 & 4.5 & 0.0 & 0.0 & 0.0 & 0.0 & 0.1 & 71.1 & 0.0 & 0.0 & 100 \\
\hline$\pi$ & 51.1 & 16.9 & 7.1 & 14.4 & 1.4 & 0.2 & 0.1 & 0.0 & 8.1 & 0.2 & 0.0 & 0.5 & 0.0 & 100 \\
\hline$R$ & 22.3 & 7.6 & 33.0 & 6.5 & 25.7 & 0.6 & 0.1 & 0.1 & 0.4 & 0.0 & 3.5 & 0.2 & 0.0 & 100 \\
\hline$\tau^{w}$ & 0.3 & 1.6 & 4.7 & 0.1 & 5.8 & 0.0 & 0.0 & 86.8 & 0.0 & 0.0 & 0.6 & 0.0 & 0.0 & 100 \\
\hline$\tau^{c}$ & 0.1 & 0.7 & 2.3 & 0.1 & 2.7 & 0.0 & 0.0 & 0.0 & 93.7 & 0.0 & 0.3 & 0.0 & 0.0 & 100 \\
\hline$\tau^{k}$ & 0.0 & 0.2 & 0.6 & 0.0 & 0.7 & 0.0 & 0.0 & 0.0 & 0.0 & 98.4 & 0.1 & 0.0 & 0.0 & 100 \\
\hline$\Delta \log \frac{W}{P}$ & 0.3 & 6.1 & 4.0 & 87.9 & 0.8 & 0.0 & 0.0 & 0.1 & 0.8 & 0.0 & 0.0 & 0.0 & 0.0 & 100 \\
\hline$\Delta \log T$ & 4.3 & 6.1 & 32.4 & 21.1 & 5.3 & 2.0 & 0.0 & 8.9 & 0.1 & 1.9 & 3.3 & 0.2 & 14.2 & 100 \\
\hline
\end{tabular}

asymptotic

\begin{tabular}{lc|c|c|c|c|c|c|c|c|c|c|c|c|c} 
& $\varepsilon^{z}$ & $\varepsilon^{\nu}$ & $\varepsilon^{b}$ & $\varepsilon^{L}$ & $\varepsilon^{m}$ & $\varepsilon^{c g}$ & $\varepsilon^{t r}$ & $\varepsilon^{\tau w}$ & $\varepsilon^{\tau c}$ & $\varepsilon^{\tau k}$ & $\varepsilon^{i}$ & $\varepsilon^{l g}$ & $\varepsilon^{t}$ & Tot \\
\hline$\Delta \log C$ & 1.5 & 12.9 & 75.8 & 2.4 & 6.2 & 0.0 & 0.1 & 0.7 & 0.2 & 0.0 & 0.1 & 0.0 & 0.0 & 100 \\
$\Delta \log I$ & 1.1 & 12.5 & 19.6 & 1.6 & 5.9 & 0.1 & 0.0 & 0.0 & 0.1 & 0.1 & 59.2 & 0.0 & 0.0 & 100 \\
$\pi$ & 70.6 & 9.3 & 3.5 & 6.0 & 5.6 & 0.5 & 0.2 & 0.9 & 1.8 & 0.7 & 0.0 & 0.9 & 0.0 & 100 \\
$R$ & 60.1 & 4.7 & 13.5 & 3.0 & 14.0 & 0.6 & 0.2 & 0.8 & 0.2 & 0.6 & 1.4 & 0.8 & 0.0 & 100 \\
$\tau^{w}$ & 33.3 & 13.9 & 2.6 & 1.3 & 27.4 & 1.5 & 0.7 & 13.3 & 0.4 & 4.0 & 0.3 & 1.3 & 0.0 & 100 \\
$\tau^{c}$ & 36.2 & 12.2 & 1.8 & 1.1 & 24.9 & 1.4 & 0.7 & 4.0 & 12.2 & 4.1 & 0.1 & 1.4 & 0.0 & 100 \\
$\tau^{k}$ & 32.3 & 9.6 & 1.3 & 0.9 & 20.1 & 1.1 & 0.5 & 3.2 & 0.3 & 29.3 & 0.1 & 1.2 & 0.0 & 100 \\
$\Delta \log \frac{W}{P}$ & 0.7 & 9.0 & 6.2 & 81.9 & 1.4 & 0.0 & 0.0 & 0.1 & 0.7 & 0.0 & 0.1 & 0.0 & 0.0 & 100 \\
$\Delta \log T$ & 4.6 & 8.4 & 34.5 & 19.1 & 7.3 & 1.8 & 0.0 & 7.6 & 0.1 & 1.6 & 3.1 & 0.2 & 11.6 & 100 \\
\hline \hline
\end{tabular}


Tax rate on labor income

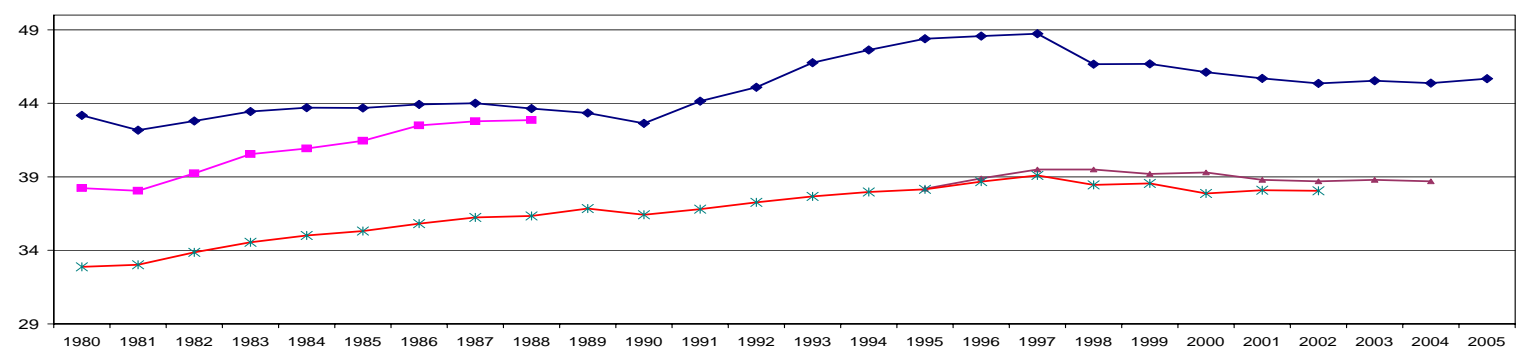

$\begin{array}{lllllllllllllllllllllllllll}1980 & 1981 & 1982 & 1983 & 1984 & 1985 & 1986 & 1987 & 1988 & 1989 & 1990 & 1991 & 1992 & 1993 & 1994 & 1995 & 1996 & 1997 & 1998 & 1999 & 2000 & 2001 & 2002 & 2003 & 2004 & 2005\end{array}$

$\rightarrow$ TAUL (MRT) $\quad$-TAUL (EUROSTAT) $\quad$-TAUL (CR) $\rightarrow$ TAUL (ours)

Tax rate on consumption

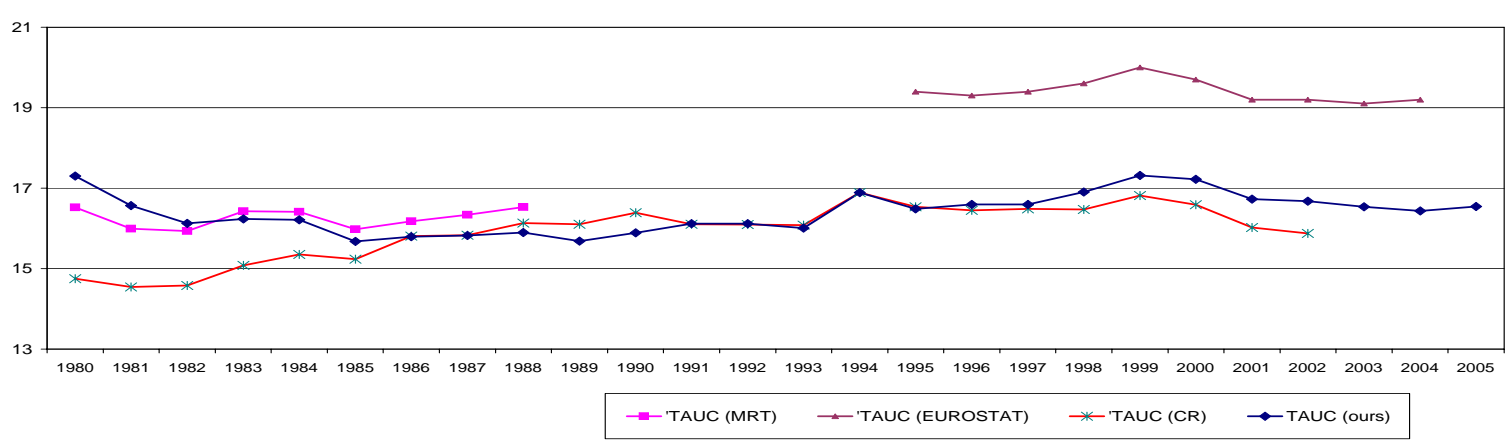

Tax rate on capital income

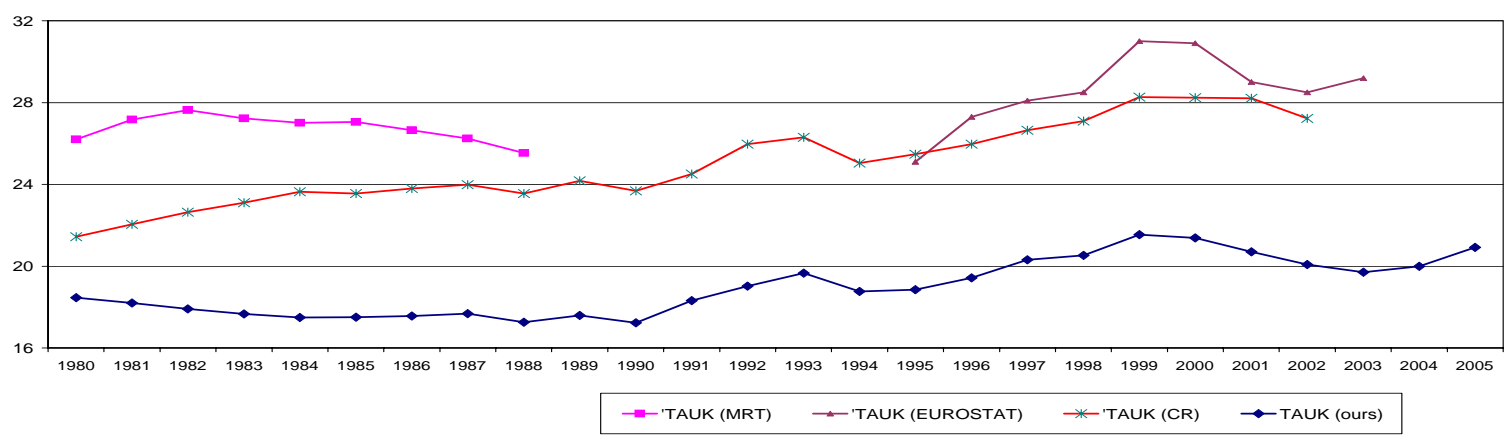

Fig. 1: Annual implicit tax rates 

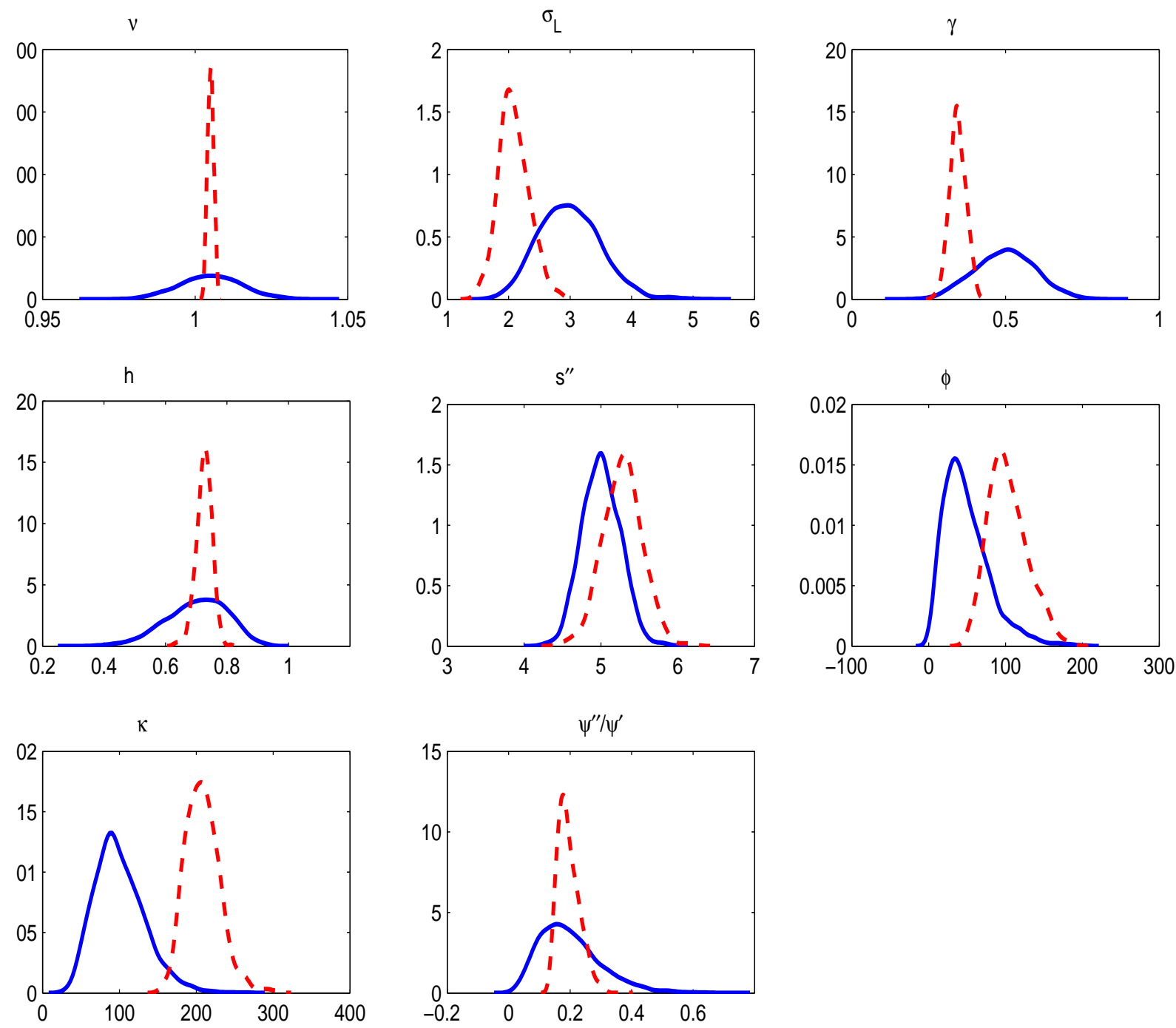

Fig.2.1: Prior (blue/solid) vs. posterior (red/dashed) distributions in MH procedure 

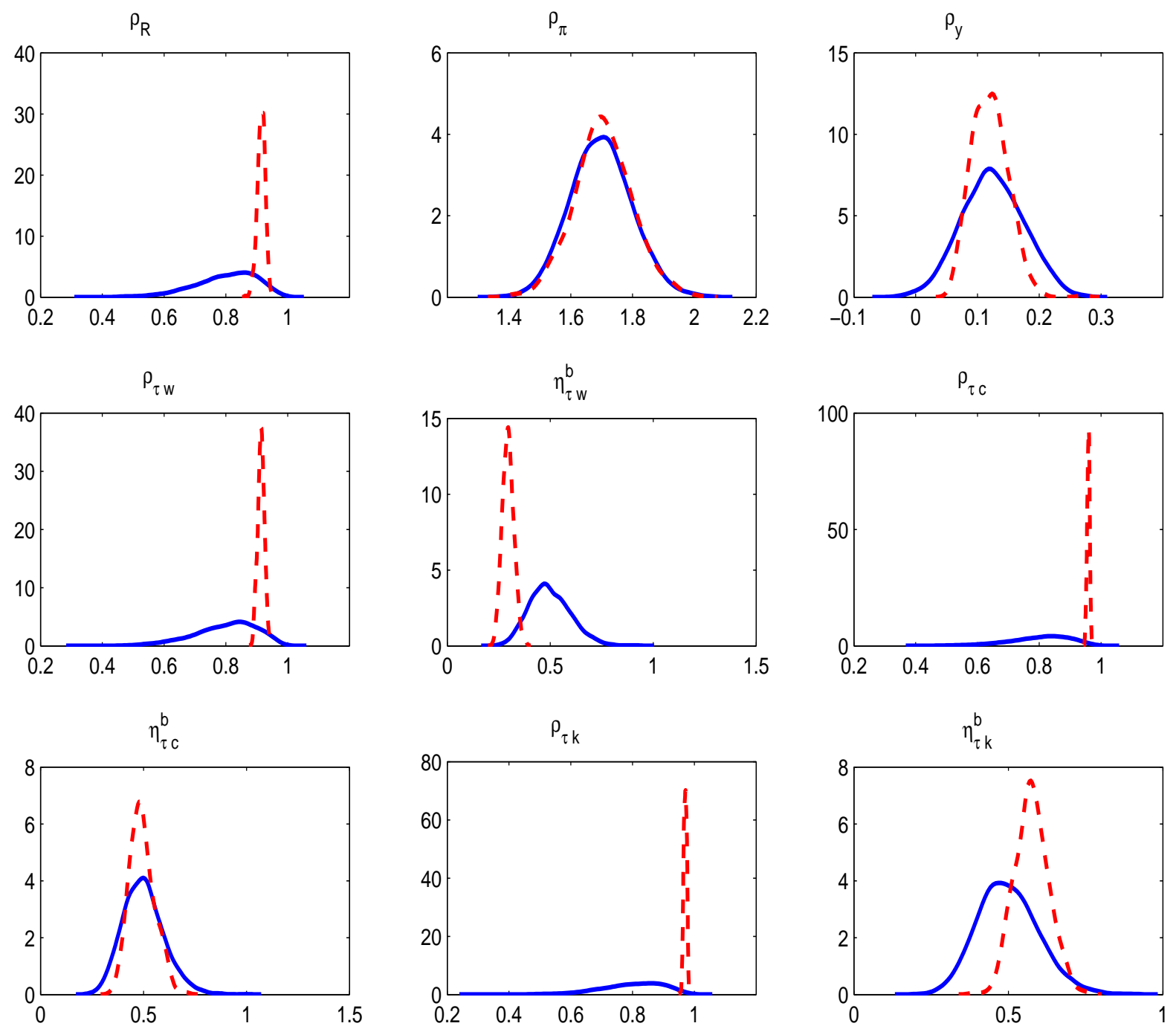

Fig.2.2: Prior (blue/solid) vs. posterior (red/dashed) distributions in MH procedure 

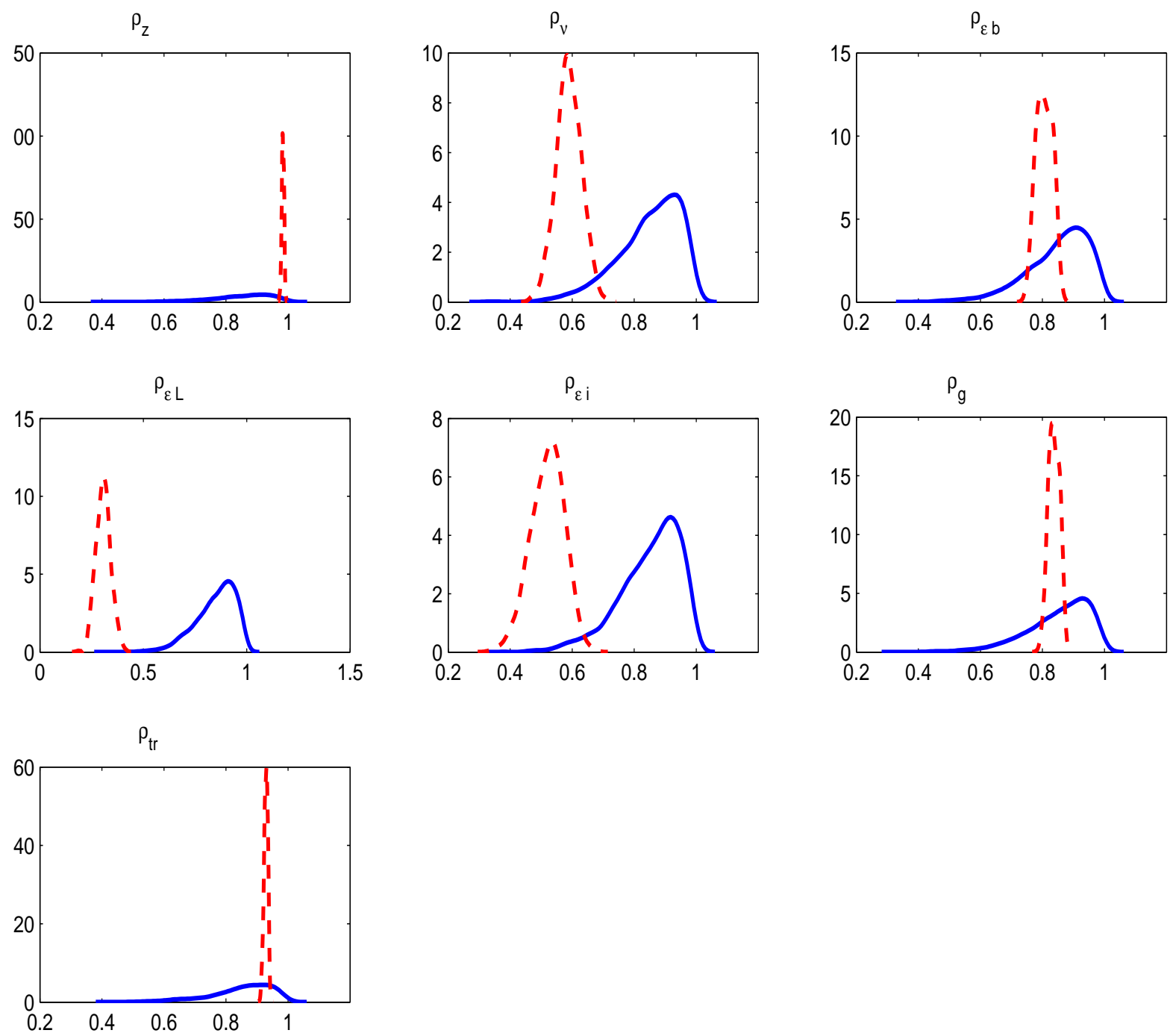

Fig.2.3: Prior (blue/solid) vs. posterior (red/dashed) distributions in MH procedure 


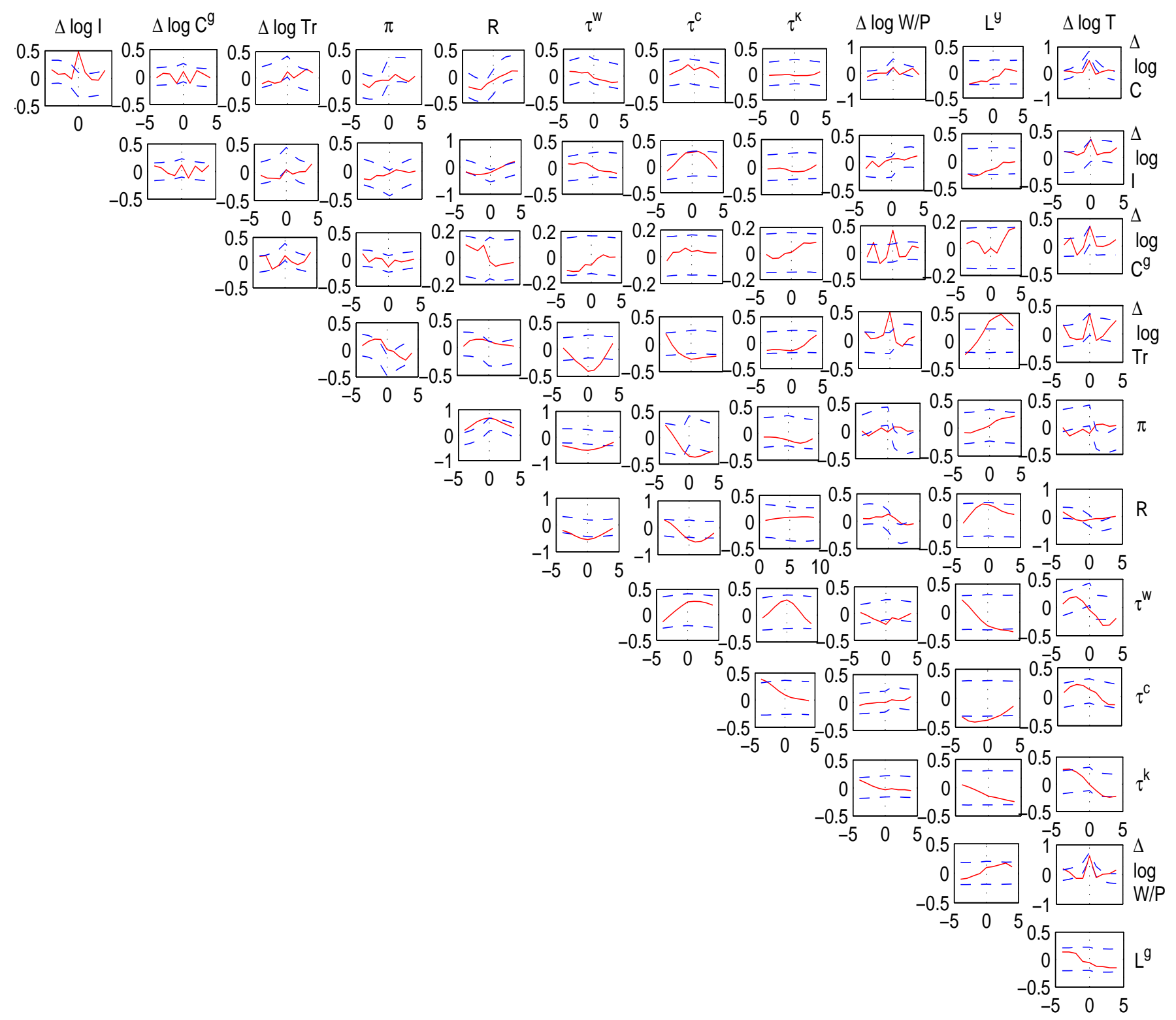

Fig. 3: Cross-correlations at $+/-4$ periods;

data (red/solid) vs. model (blue/dashed $90 \%$ confidence bands) 

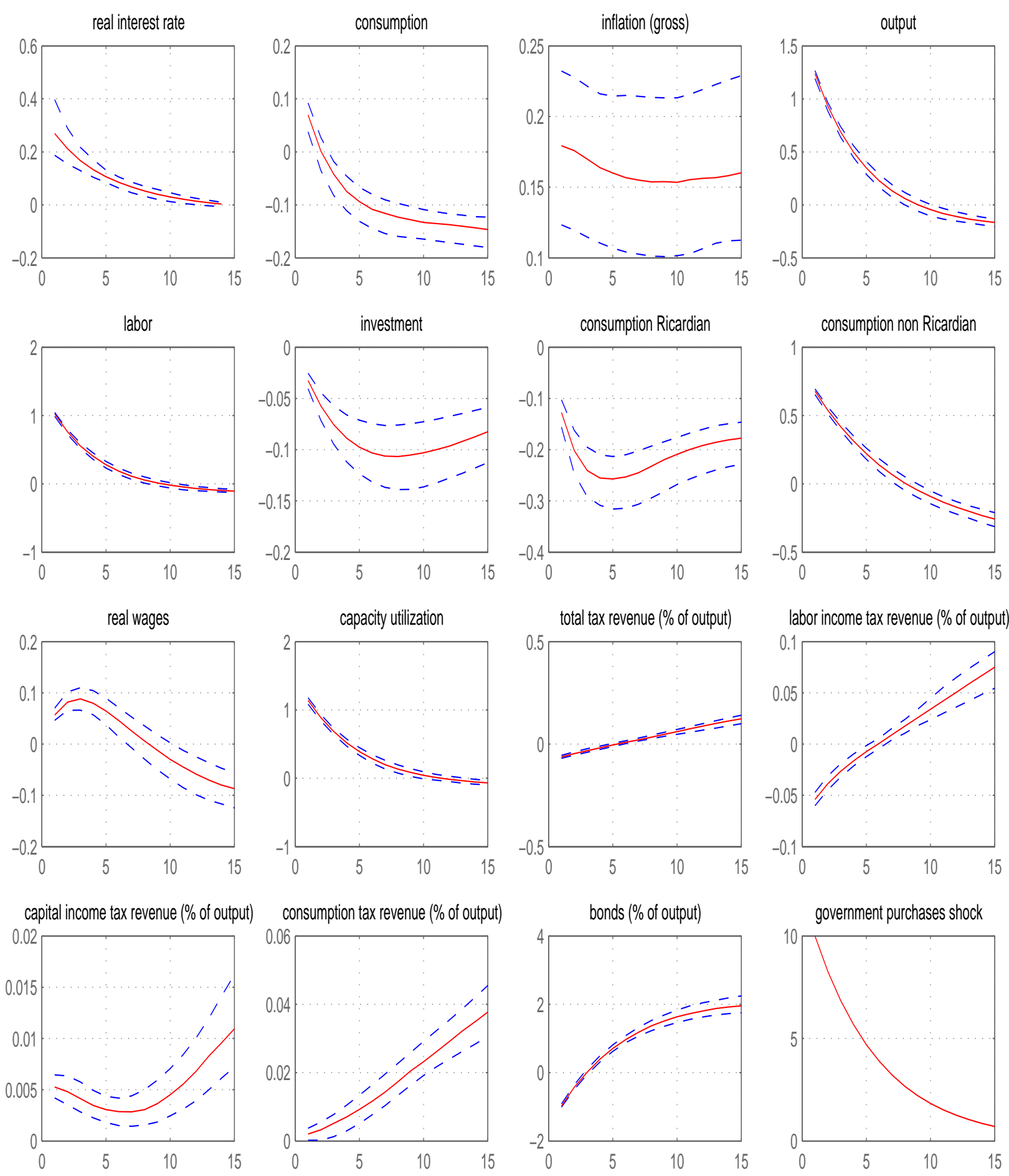

Fig. 4: Responses after a government purchases shock 

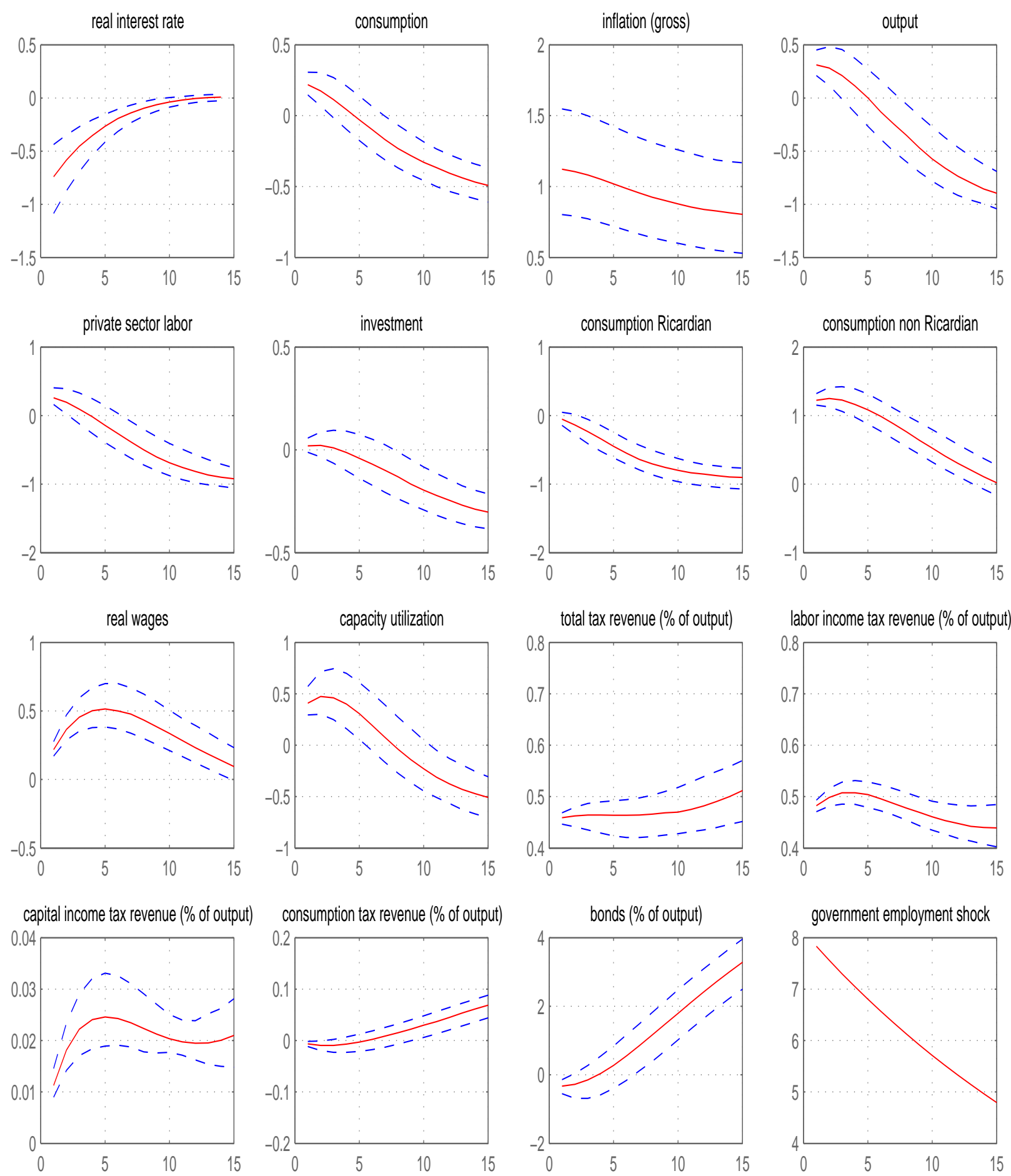

Fig. 5: Responses after a government employment shock 

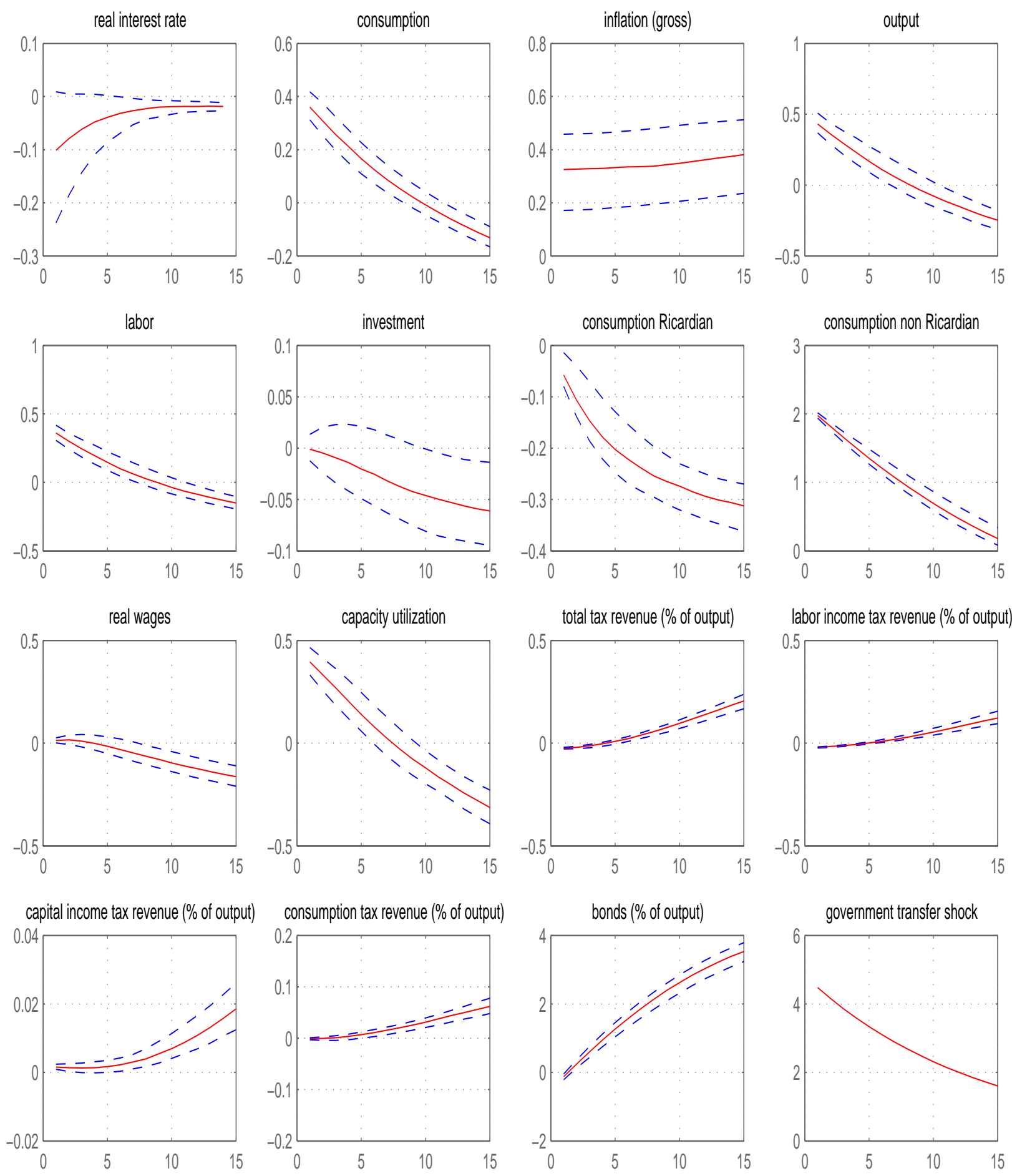

Fig. 6: Responses after a transfers shock 

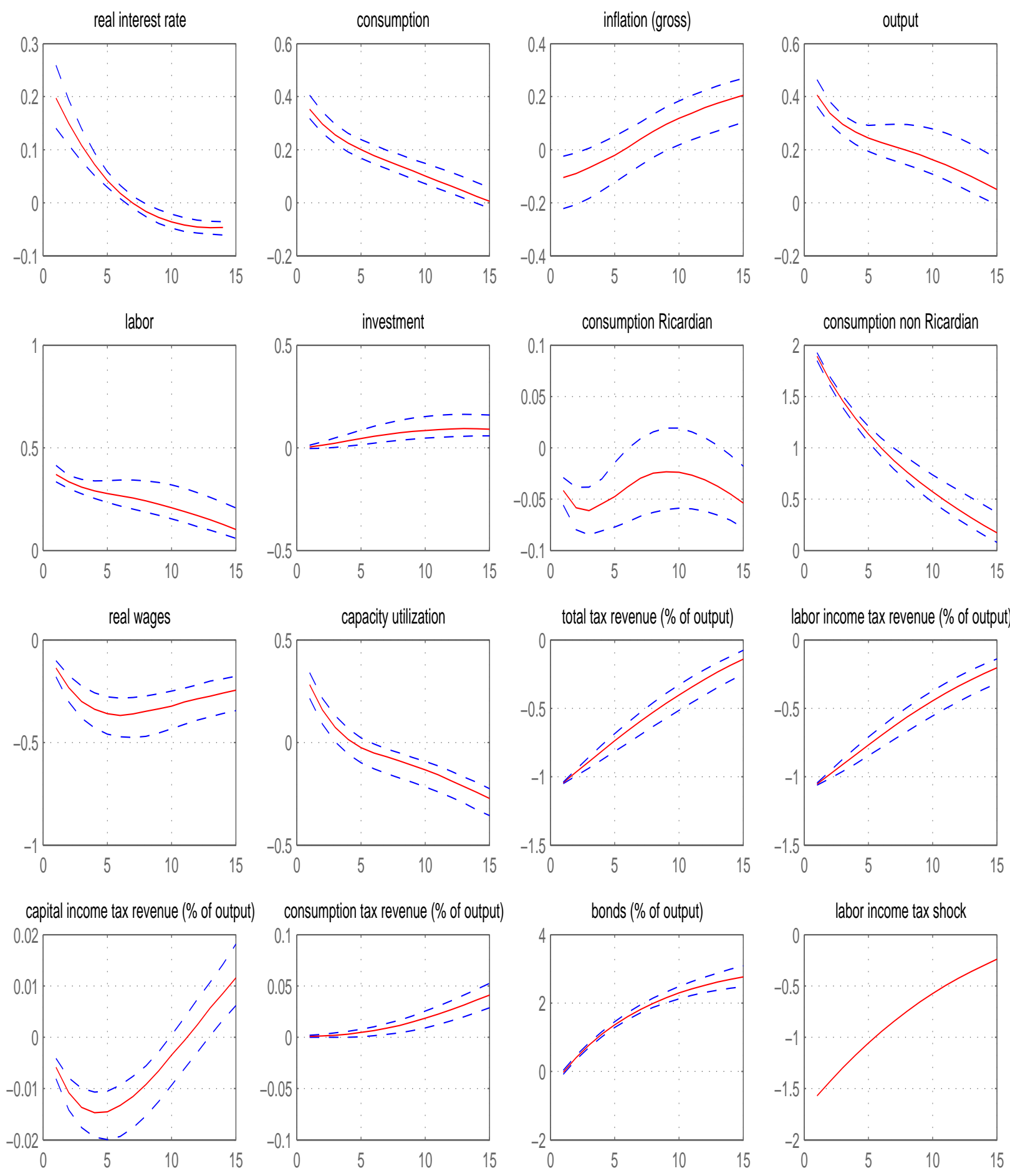

Fig. 7: Responses after a labor income tax shock 

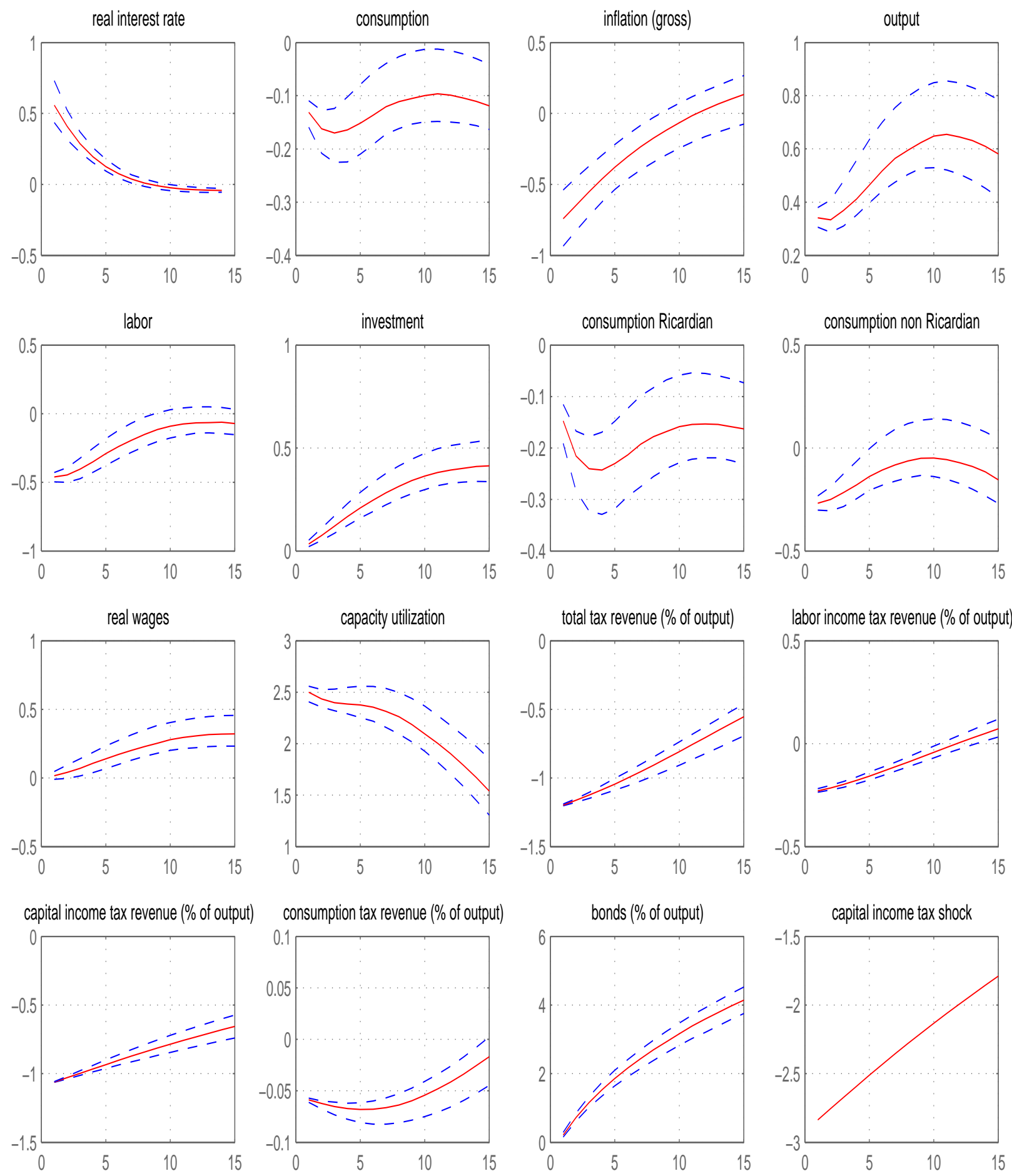

Fig. 8: Responses after a capital income tax shock 

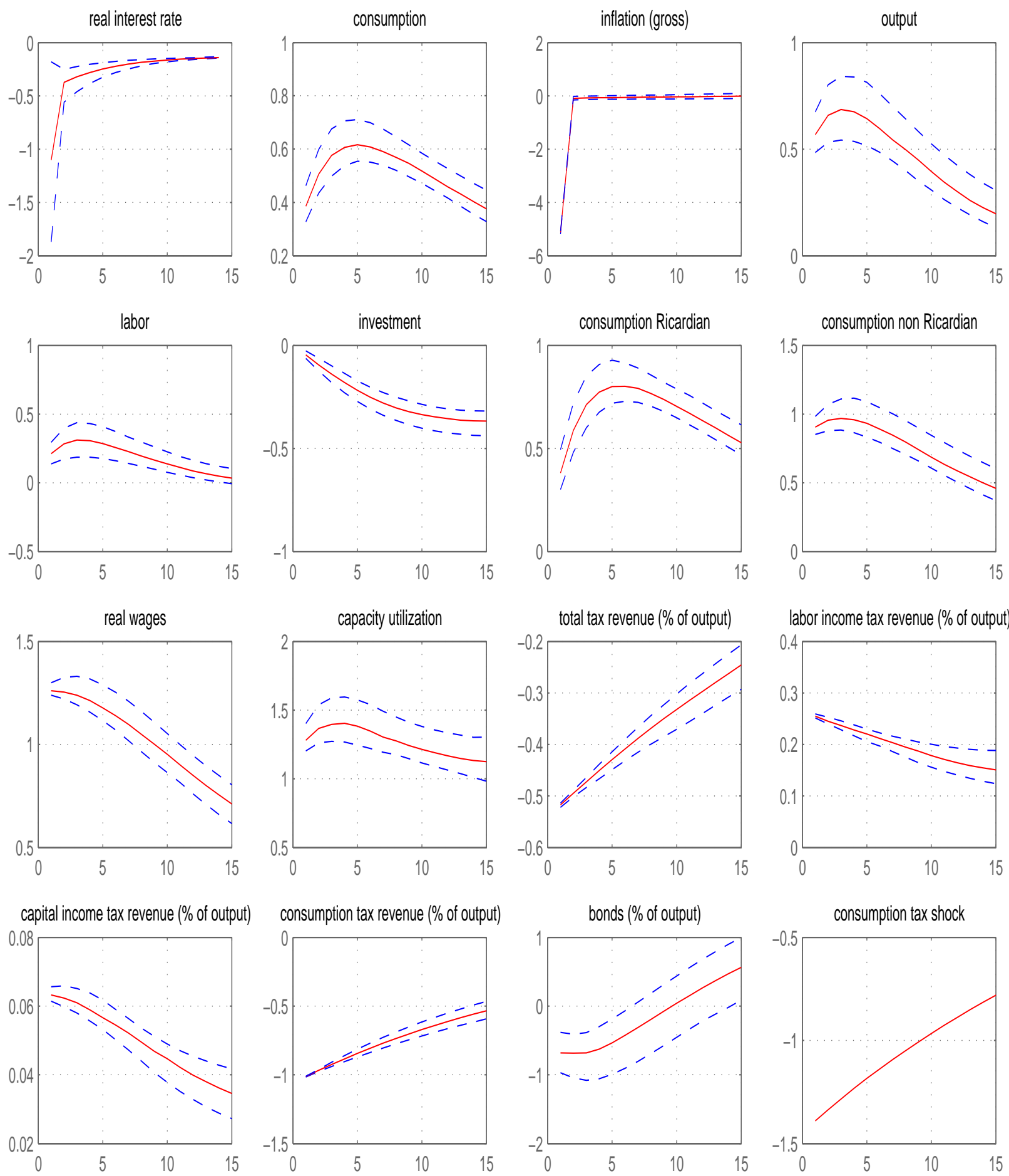

Fig. 9: Responses after a consumption tax shock 

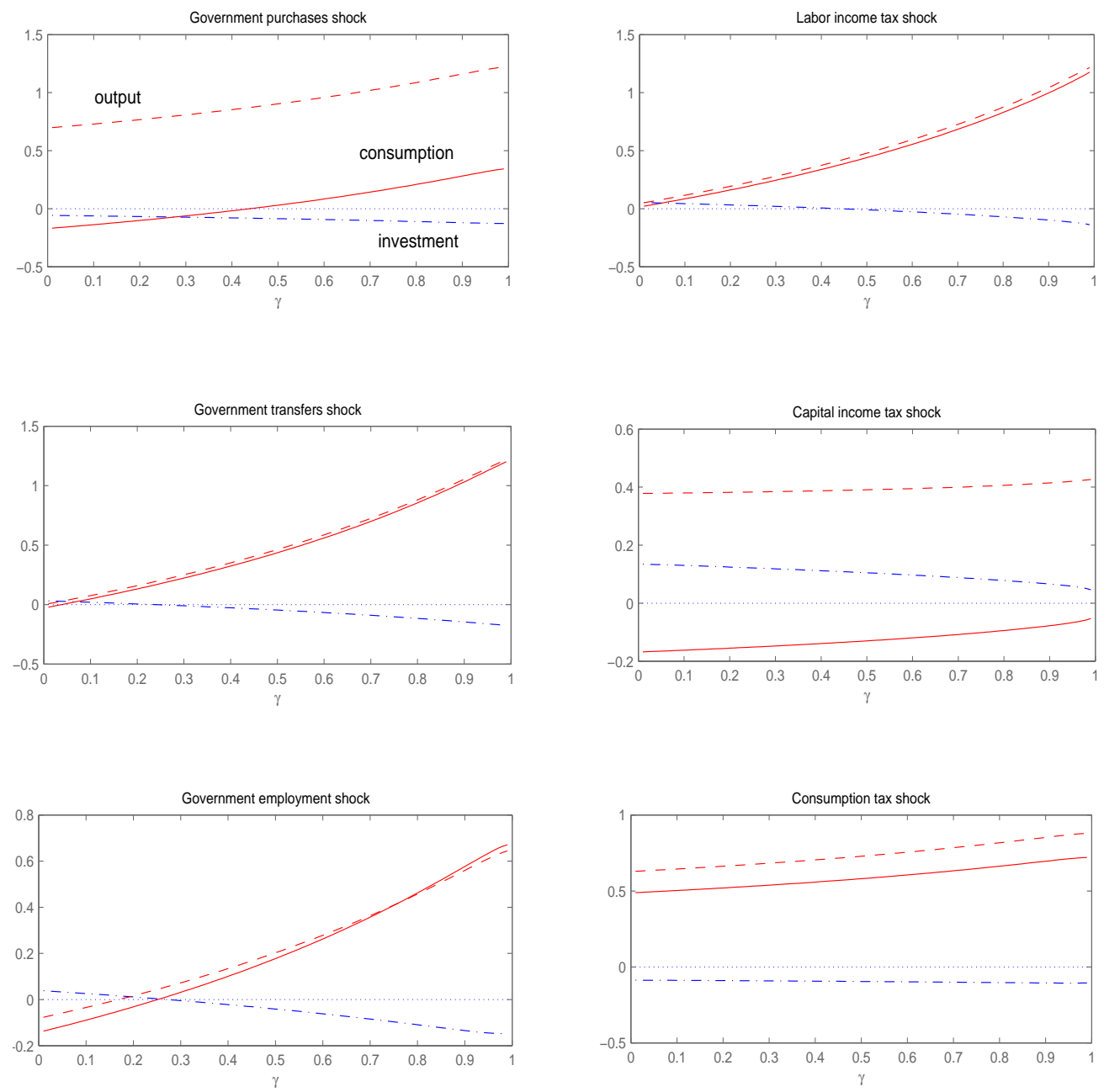

Fig. 10: Robustness - First year average responses of output, consumption and investment to fiscal shocks for different shares of non-Ricardian agents 